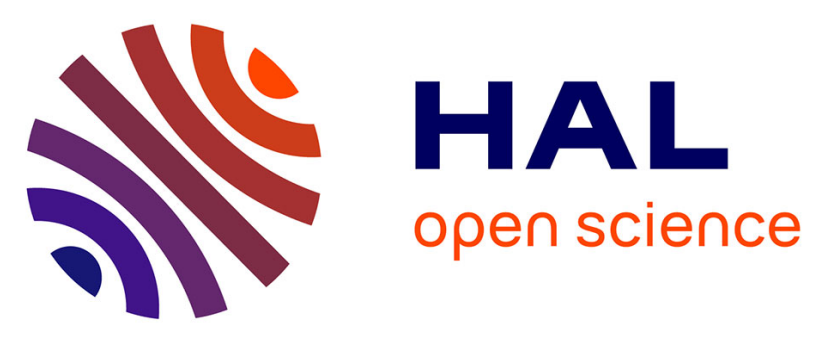

\title{
A Theoretical Study of the Wet Removal of Atmospheric Pollutants. Part I: The Redistribution of Aerosol Particles Captured through Nucleation and Impaction Scavenging by Growing Cloud Drops
}

\author{
Andrea I. Flossmann, W. Hall, H. Pruppacher
}

\section{To cite this version:}

Andrea I. Flossmann, W. Hall, H. Pruppacher. A Theoretical Study of the Wet Removal of Atmospheric Pollutants. Part I: The Redistribution of Aerosol Particles Captured through Nucleation and Impaction Scavenging by Growing Cloud Drops. Journal of the Atmospheric Sciences, 1985, 42 (6), pp.583 - 606. 10.1175/1520-0469(1985)0422.0.CO;2 . hal-01905670

\author{
HAL Id: hal-01905670 \\ https://hal.uca.fr/hal-01905670
}

Submitted on 11 Jun 2021

HAL is a multi-disciplinary open access archive for the deposit and dissemination of scientific research documents, whether they are published or not. The documents may come from teaching and research institutions in France or abroad, or from public or private research centers.
L'archive ouverte pluridisciplinaire HAL, est destinée au dépôt et à la diffusion de documents scientifiques de niveau recherche, publiés ou non, émanant des établissements d'enseignement et de recherche français ou étrangers, des laboratoires publics ou privés. 


\title{
A Theoretical Study of the Wet Removal of Atmospheric Pollutants. Part I: The Redistribution of Aerosol Particles Captured through Nucleation and Impaction Scavenging by Growing Cloud Drops
}

\author{
A. I. FLOSSMANN* \\ Meteorologisches Institut, Johannes Gutenberg University, Mainz, FRG \\ W. D. HALL \\ National Center for Atmospheric Research, ** Boulder, CO 80307 \\ H. R. PRUPPACHER*** \\ Department of Atmospheric Sciences, University of California, Los Angeles, CA 40524
}

(Manuscript received 1 June 1984, in final form 21 November 1984)

\section{ABSTRACT}

\begin{abstract}
A theoretical model is formulated which allows the processes that control the wet deposition of atmospheric pollutants to be included in cloud dynamic models. The model considers the condensation process and the collision-coalescence process which, coupled together, control the fate of atmospheric aerosol particles removed by clouds and precipitation through nucleation scavenging and impaction scavenging. The model was tested by substituting a simple parcel model for the dynamic framework. In this form the model was used to determine the time evolution of the aerosol particle mass scavenged by drops as well as the aerosol particle mass left unactivated in air as "drop-interstitial" aerosol. In the present computation all aerosol particles are assumed to have the same composition. Our study shows for inside cloud scavenging: 1) collision and coalescence causes among the various drop size categories a redistribution of the scavenged aerosol particles in such a manner that the main aerosol particle mass is always associated with the main water mass, thus ensuring that if a cloud reaches the precipitation stage it will also return to the ground the main aerosol particle mass scavenged by the cloud; 2) although the main aerosol particle mass is contained in the large drops, the mass mixing ratio of the captured aerosol in the cloud water is larger inside smaller drops than inside larger drops, implying that smaller drops are more contaminated than larger ones; 3) through nucleation scavenging the total number concentration of aerosol particles is predicted to become reduced by 48 to $94 \%$ depending on the composition of the particles, the reduction being mainly confined to aerosol particles larger than $0.1 \mu \mathrm{m}$ in radius. This implies that a drop interstitial aerosol exists that consists of a particle population reduced in number concentration by up to $94 \%$ and reduced in mass by several orders of magnitude, as compared to the particle concentration outside the cloud. 4) Although the aerosol particle mass scavenged by impaction scavenging cannot completely be neglected in accounting for the total amount of aerosol particle mass scavenged by clouds, it is smaller by several orders of magnitude than the aerosol particle mass removed by nucleation scavenging.
\end{abstract}

\section{Introduction}

It has been well established that the loading of the atmosphere by aerosol particles is determined on the one hand by the rate at which these particles are introduced into the atmosphere and, on the other hand, by the rate at which the particles are removed by dry and wet deposition involving clouds and precipitation. In warm clouds, with which we shall

\footnotetext{
* Part of a Ph.D. thesis.

* The National Center for Atmospheric Research is sponsored by the National Science Foundation.

*** Current affiliation: Meteorologisches Institut, Johannes Gutenberg University, Mainz, FRG.
}

be exclusively concerned here, wet deposition operates via the removal of aerosol particles by condensation (nucleation scavenging), i.e., by transforming some of the aerosol particles into drops as a result of drop nucleation from the vapor, and via the removal of aerosol particles by impaction (impaction scavenging), i.e., by attaching aerosol particles to cloud and rain drops through the mechanisms of Brownian diffusion, inertia, hydrodynamic forces and through phoretic and electric forces, and via the transport of the scavenged materials to the ground. The efficiency with which impaction scavenging operates has been discussed on the basis of theoretical studies and laboratory tests by Barlow and Latham (1983), Leong et al. (1982), Carstens and Martin (1982), Wang et 
al. (1978), Lai et al. (1978), Grover et al. (1977), Wang and Pruppacher (1977), Kerker and Hampl (1974) and Hampl et al. (1971). Due to the difficulties in controlling and measuring the ambient conditions, field studies, on the other hand, have thus far not yet led to quantitative data on the efficiency of impaction scavenging. An exception to this are the field observations of Radke et al. (1980) who deduced impaction scavenging efficiencies considerably larger than those theoretically predicted.

Little is known of the efficiency with which aerosol particles are scavenged by nucleation. Field observations of Radke (1983) and of Hegg and Hobbs (1983) suggest, however, that nucleation scavenging is of considerable importance to the overall scavenging mechanism. From their field observations they concluded that most of the sulfate mass inside a cloud enters a drop via drop nucleation on sulfate particles, while a smaller amount of sulfate enters by gas scavenging via oxidation to sulfate of the scavenged $\mathrm{SO}_{2}$, and a comparatively much smaller amount enters via impaction scavenging of sulfate particles. They also deduced that through nucleation scavenging the total number concentration of aerosol particles decreases by 80 to $92 \%$ across the cloud base as a result of nucleation scavenging, whereby the particles of radii larger than $0.1 \mu \mathrm{m}$ are most efficiently reduced. Since the results on nucleation scavenging are only based on relatively crude estimates, further quantitative studies are needed to arrive at a general view of the relative importance of nucleation and impaction scavenging, both of which not only determine the amount of aerosol particle mass inside the cloud water but also control the aerosol particle population located in the air between the cloud drops (cloud interstitial aerosol).

A study of literature further illustrates that little is known of the fate of the aerosol particles once they have been captured by cloud drops through nucleation and impaction scavenging. Thus, it is expected that during the growth of cloud drops by the stochastic collision-coalescence process a substantial redistribution of the aerosol mass would take place. This expectation raises the question of whether during this redistribution the aerosol particle loading will prefer certain drop size classes.

In order to shed more light on this question, we have developed a theoretical model in which the condensation process, the collision-coalescence process, and the process of impaction scavenging of aerosol particles are coupled in such a manner that for a given aerosol type and particle size distribution, the evolution in time of the aerosol mass inside the drops and the aerosol mass remaining in the air as drop-interstitial aerosol can be determined.

\section{The present model}

In the present study we formulated a theoretical model that 1) describes the time evolution of a drop size distribution originating on aerosol particles of a given size distribution and of given uniform composition and its subsequent growth by condensation and collision and coalescence; 2) describes the simultaneous time evolution of the aerosol particle mass captured by and redistributed among the various cloud drop size categories; and 3) describes the simultaneous time evolution of the mass and distribution of the aerosol particles left unactivated in the air as drop interstitial aerosol.

This model is formulated theoretically in a general manner by means of a self-consistent set of equations to be used in conjunction with a convective cloud model which predicts the dynamic and thermodynamic input parameters. Before linking the present scavenging model to a detailed convective cloud model, we decided to test it under simplified conditions, i.e., by linking it with an entrainment parcel model. The present article describes the numerical evaluation of our model in the latter form, leaving an evaluation inside the framework of a dynamic model to a later communication.

Introducing the number and mass density functions $f_{\mathrm{d}}, f_{\mathrm{APa}}, g_{\mathrm{APd}}$ and $g_{\mathrm{APa}}$ (see list of symbols in the Appendix) for the drops in air, and the aerosol particles in air and in the cloud water, we may express the time rate of change of the drop number density distribution function by

$$
\begin{aligned}
& \frac{\partial f_{\mathrm{d}}(m)}{\partial t}=-\nabla \cdot\left[\mathbf{v} f_{\mathrm{d}}(m)\right]+\nabla \cdot\left[K_{m} \nabla f_{\mathrm{d}}(m)\right] \\
& +\frac{\partial}{\partial z}\left[V_{\mathrm{o}}(m) f_{\mathrm{d}}(m)\right]+\left.\frac{\partial f_{\mathrm{d}}(m)}{\partial t}\right|_{\mathrm{act}}+\left.\frac{\partial f_{\mathrm{d}}(m)}{\partial t}\right|_{\text {con/eva }} \\
& \quad+\left.\frac{\partial f_{\mathrm{d}}(m)}{\partial t}\right|_{\mathrm{AP}, \text { coll }}+\left.\frac{\partial f_{\mathrm{d}}(m)}{\partial t}\right|_{\mathrm{d}, \text { coal }}+\left.\frac{\partial f_{\mathrm{d}}(m)}{\partial t}\right|_{\mathrm{d}, \text { break up }}
\end{aligned}
$$

the time rate of change of the number density distribution function for the aerosol particles remaining in the air by

$$
\begin{aligned}
\frac{\partial f_{\mathrm{APa}}\left(m_{\mathrm{AP}}\right)}{\partial t}=-\nabla \cdot\left[\mathbf{v} f_{\mathrm{APa}}\left(m_{\mathrm{AP}}\right)\right]+\nabla \cdot\left[K_{m} \nabla f_{\mathrm{APa}}\left(m_{\mathrm{AP}}\right)\right] \\
+\left.\frac{\partial f_{\mathrm{APa}}\left(m_{\mathrm{AP}}\right)}{\partial t}\right|_{\mathrm{act}}+\left.\frac{\partial f_{\mathrm{APa}}\left(m_{\mathrm{AP}}\right)}{\partial T}\right|_{\text {con } / \mathrm{eva}} \\
+\left.\frac{\partial f_{\mathrm{APa}}\left(m_{\mathrm{AP}}\right)}{\partial t}\right|_{\mathrm{AP}, \text { coll }}
\end{aligned}
$$

the time rate of change of the mass density distribution function of aerosol particles in the drops by

$$
\begin{gathered}
\frac{\partial g_{\mathrm{APd}}(m)}{\partial t}=-\nabla \cdot\left[\mathbf{v} g_{\mathrm{APd}}(m)\right]+\nabla \cdot\left[K_{m} \nabla g_{\mathrm{APd}}(m)\right] \\
+\frac{\partial}{\partial z}\left[V_{\infty}(m) g_{\mathrm{APd}}(m)\right]+\left.\frac{\partial g_{\mathrm{APd}}(m)}{\partial t}\right|_{\mathrm{act}}
\end{gathered}
$$




$$
\begin{aligned}
& +\left.\frac{\partial g_{\mathrm{APd}}(m)}{\partial t}\right|_{\text {con/eva }}+\left.\frac{\partial g_{\mathrm{APd}}(m)}{\partial t}\right|_{\mathrm{AP}, \text { coll }} \\
& \quad+\left.\frac{\partial g_{\mathrm{APd}}(m)}{\partial t}\right|_{\mathrm{d}, \text { coal }}+\left.\frac{\partial g_{\mathrm{APd}}(m)}{\partial t}\right|_{\mathrm{d}, \text { break up }} ;
\end{aligned}
$$

and the time rate of change of the mass density distribution function for the aerosol particles remaining in the air by

$$
\begin{aligned}
\frac{\partial g_{\mathrm{APa}}(m)}{\partial t}=-\nabla \cdot\left[v g_{\mathrm{APa}}\left(m_{\mathrm{AP}}\right)\right]+\nabla \cdot\left[K_{m} \nabla g_{\mathrm{APa}}\left(m_{\mathrm{AP}}\right)\right] \\
+\left.\frac{\partial g_{\mathrm{APa}}\left(m_{\mathrm{AP}}\right)}{\partial t}\right|_{\mathrm{act}}+\left.\frac{\partial g_{\mathrm{APa}}\left(m_{\mathrm{AP}}\right)}{\partial t}\right|_{\text {con } / \mathrm{eva}} \\
+\left.\frac{\partial g_{\mathrm{APa}}\left(m_{\mathrm{AP}}\right)}{\partial t}\right|_{\mathrm{AP}, \text { coll }}
\end{aligned}
$$

For the physical meaning of the terms with subscripts on the second line of Eqs. (1)-(4) see Appendix.

While the first three terms in Eqs. (1) and (3) and the first two terms in Eqs. (2) and (4) must be evaluated from the dynamic framework of the chosen dynamic cloud model, the remaining microphysical terms can be evaluated from the relations below.

The time rate of change of the drop spectrum due to collision and coalescence between the drop is

$$
\begin{gathered}
\left.\frac{\partial f_{\mathrm{d}}(m)}{\partial t}\right|_{\mathrm{d}, \text { coal }}=\int_{0}^{m / 2} f_{\mathrm{d}}\left(m-m^{\prime}\right) f_{\mathrm{d}}\left(m^{\prime}\right) K_{\mathrm{d}}\left(m-m^{\prime}, m^{\prime}\right) \\
\times d m^{\prime}-\int_{0}^{\infty} f_{\mathrm{d}}(m) f_{\mathrm{d}}\left(m^{\prime}\right) K_{\mathrm{d}}\left(m, m^{\prime}\right) d m^{\prime} .
\end{gathered}
$$

The time rate of change of the aerosol particle mass inside the drop growing by collision and coalescence is

$$
\begin{gathered}
\left.\frac{\partial g_{\mathrm{APd}}(m)}{\partial t}\right|_{\mathrm{d}, \text { coal }}=\int_{0}^{m / 2}\left[Q_{\mathrm{APd}}\left(m^{\prime}\right) m^{\prime}+Q_{\mathrm{APd}}\left(m-m^{\prime}\right)\right. \\
\left.\times\left[m-m^{\prime}\right]\right] f_{\mathrm{d}}\left(m^{\prime}\right) f_{\mathrm{d}}\left(m-m^{\prime}\right) K_{\mathrm{d}}\left(m-m^{\prime}, m^{\prime}\right) d m^{\prime} \\
-g_{\mathrm{APd}}(m) \int_{0}^{\infty} f_{\mathrm{d}}\left(m^{\prime}\right) K_{\mathrm{d}}\left(m, m^{\prime}\right) d m^{\prime},
\end{gathered}
$$

in which we have introduced the new variable $Q_{\mathrm{APd}}$ (defined in the Appendix) in order to improve the computational efficiency by reformulating Eq. (6) as

$$
\begin{aligned}
\left.\frac{\partial g_{\mathrm{APd}}(m)}{\partial t}\right|_{\mathrm{d}, \text { coal }}=\left.m f_{\mathrm{d}}(m) \frac{\partial Q_{A P d}(m)}{\partial t}\right|_{\mathrm{d}, \text { coal }} & \\
& +\left.m Q_{\mathrm{APd}}(m) \frac{\partial f_{\mathrm{d}}(m)}{\partial t}\right|_{\mathrm{d}, \text { coal }},
\end{aligned}
$$

with $\left.\frac{\partial f_{\mathrm{d}}(m)}{\partial t}\right|_{\mathrm{d} \text {, coal }}$ given by Eq. (5), with

$\left.\frac{\partial Q_{\mathrm{APd}}(m)}{\partial t}\right|_{\mathrm{d}, \text { coal }}=\frac{1}{m f_{\mathrm{d}}(m)} \int_{0}^{m / 2}\left[Q_{\mathrm{APd}}\left(m^{\prime}\right) m^{\prime}\right.$

$$
\begin{aligned}
+ & \left.Q_{\mathrm{APd}}\left(m-m^{\prime}\right) \cdot\left(m-m^{\prime}\right)-Q_{\mathrm{APd}}(m) m\right] \\
& \times f_{\mathrm{d}}\left(m^{\prime}\right) f_{\mathrm{d}}\left(m-m^{\prime}\right) K_{\mathrm{d}}\left(m-m^{\prime}, m^{\prime}\right) d m^{\prime} .
\end{aligned}
$$

The terms

$$
\left.\frac{\partial f_{\mathrm{d}}(m)}{\partial t}\right|_{\mathrm{d}, \text { break up }},\left.\frac{\partial g_{\mathrm{APd}}(m)}{\partial t}\right|_{\mathrm{d}, \text { break up }}
$$

in Eqs. (1) and (3) were evaluated by using the drop breakup procedure used by Hall (1980), which was modeled after Danielson et al. (1972). This procedure parameterizes the drop breakup process as a spontaneous breakup of droplets larger than a specific size. Upon the appearance of such size drops the drop mass is instantaneously redistributed according to the reference spectrum prescribed by Hall (1980, his Table 2).

The rate at which the number of aerosol particles in air is reduced due to being captured by the growing drops is

$$
\begin{aligned}
& \left.\frac{\partial f_{\mathrm{APa}}\left(m_{\mathrm{AP}}\right)}{\partial t}\right|_{\mathrm{AP}, \text { coll }} \\
& =-\int_{0}^{\infty} f_{\mathrm{APa}}\left(m_{\mathrm{AP}}\right) f_{\mathrm{d}}(m) K_{\mathrm{AP}}\left(m_{\mathrm{AP}}, m\right) d m,
\end{aligned}
$$

and the rate at which aerosol mass is reduced by capture is

$$
\begin{aligned}
\left.\frac{\partial g_{\mathrm{APa}}\left(m_{\mathrm{AP}}\right)}{\partial t}\right|_{\mathrm{AP}, \text { coll }} & \\
= & -\int_{0}^{\infty} g_{\mathrm{APa}}\left(m_{\mathrm{AP}}\right) f_{\mathrm{d}}(m) K_{\mathrm{AP}}\left(m_{\mathrm{AP}}, m\right) d m .
\end{aligned}
$$

This capture process contributed aerosol particlemass and water mass to the drops. The resulting increase in mass of the drops changes the drop spectrum according to

$$
\left.\frac{\partial f_{\mathrm{d}}(m)}{\partial t}\right|_{\mathrm{AP}, \text { coll }}=-\frac{\partial}{\partial m}\left(\left.\frac{d m}{d t}\right|_{\mathrm{AP}, \text { coll }]} f_{\mathrm{d}}(m)\right),
$$

with

$$
\left.\frac{d m}{d t}\right|_{\mathrm{AP}, \text { coll }}=\int_{0}^{\infty} m_{\mathrm{AP}} f_{\mathrm{APa}}\left(m_{\mathrm{AP}}\right) K_{\mathrm{AP}}\left(m_{\mathrm{AP}}, m\right) d m_{\mathrm{AP}} .
$$

The time rate of change of aerosol particle mass inside the drops resulting from the capture of aerosol particle is

$$
\begin{gathered}
\left.\frac{\partial g_{\mathrm{APd}}(m)}{\partial t}\right|_{\mathrm{AP}, \text { coll }}=f_{\mathrm{d}}(m) \int_{0}^{\infty} g_{\mathrm{APa}}\left(m_{\mathrm{AP}}\right) K_{\mathrm{AP}}\left(m_{\mathrm{AP}}, m\right) \\
\times d m_{\mathrm{AP}}-\frac{\partial}{\partial m}\left[\left.\frac{d m}{d t}\right|_{\mathrm{AP}, \text { coll }} g_{\mathrm{APd}}(m)\right],
\end{gathered}
$$

wherein the first term on the right-hand side of Eq. (12) represents the contribution due to the collection 
of aerosol particles, and the second term on the righthand side represents the contribution due to the shift of the whole drop number distribution resulting from the drop growth by intake of aerosol particles.

The time rate of change of the drop spectrum due to the condensation or evaporation of drops is

$$
\left.\frac{\partial f_{\mathrm{d}}(m)}{\partial t}\right|_{\text {con/eva }}=-\frac{\partial}{\partial m}\left(\left.\frac{d m}{d t}\right|_{\text {con/eva }} f_{\mathrm{d}}(m)\right) \text {. }
$$

The corresponding time rate of change of the aerosol particle mass inside drops of a given size category is

$$
\left.\frac{\partial g_{\mathrm{APd}}(m)}{\partial t}\right|_{\text {con/eva }}=-\frac{\partial}{\partial m}\left[\left.\frac{d m}{d t}\right|_{\text {con/eva }} g_{\mathrm{APd}}(m)\right],
$$

where from Pruppacher and Klett (1978, their Eqs. 13-28)

$$
\begin{aligned}
& \left.\frac{d m}{d t}\right|_{\text {con/eva }} \\
& =4 \pi a \frac{\left[s_{v w}-\frac{2 \sigma_{\mathrm{ua}} M_{w}}{\mathscr{R} T \rho_{\mathrm{w}} a}+\frac{\nu \epsilon \Phi_{s} M_{w} \rho_{\mathrm{AP}} r_{N}^{3}}{M_{s} \rho_{w}\left(a^{3}-r_{N}{ }^{3}\right)}\right] F_{v}}{\frac{L_{e}}{k_{\mathrm{a}}^{*} T}\left(\frac{L_{e} M_{w}}{\mathcal{R} T}-1\right)+\frac{\mathscr{R} T}{M_{w} e_{\text {sat }, w} D_{v}^{*}}} .
\end{aligned}
$$

In the present model the growth by vapor diffusion of the unactivated drops were also considered, for which

$$
\begin{aligned}
& \left.\frac{\partial f_{\mathrm{APa}}\left(m_{\mathrm{AP}}\right)}{\partial t}\right|_{\mathrm{con} / \mathrm{eva}} \\
& =-\frac{\partial}{\partial m_{\mathrm{AP}}}\left[\left.\frac{d m_{\mathrm{AP}}}{d t}\right|_{\text {con/eva }} f_{\mathrm{APa}}\left(m_{\mathrm{AP}}\right)\right], \\
& \begin{aligned}
\left.\frac{\partial g_{\mathrm{APa}}\left(m_{\mathrm{AP}}\right)}{\partial t}\right|_{\text {con/eva }} \\
=-\frac{\partial}{\partial m_{\mathrm{AP}}}\left[\left.\frac{d m_{\mathrm{AP}}}{d t}\right|_{\text {con } / \mathrm{eva}} g_{\mathrm{APa}}\left(m_{\mathrm{AP}}\right)\right],
\end{aligned}
\end{aligned}
$$

with

$$
\begin{aligned}
&\left.\frac{d m_{\mathrm{AP}}}{d t}\right|_{\text {con/eva }} \\
&=4 \pi r \frac{\left[s_{v w}-\frac{2 \sigma_{w / \mathrm{a}} M_{w}}{\mathscr{R} T \rho_{w} r}+\frac{\nu \epsilon \Phi_{s} M_{w} \rho_{\mathrm{AP}} r_{N}{ }^{3}}{M_{s} \rho_{w}\left(r^{3}-r_{N}{ }^{3}\right)}\right] F_{v}}{\frac{L_{e}}{k_{\mathrm{a}}^{*} T}\left(\frac{L_{e} M}{R T}-1\right)+\frac{\mathscr{R} T}{M_{w} e_{\mathrm{sat}, w} D_{v}^{*}}}
\end{aligned}
$$

The quantities

$$
\begin{aligned}
& \left.\frac{\partial f_{\mathrm{d}}(m)}{\partial t}\right|_{\mathrm{act}},\left.\quad \frac{\partial g_{\mathrm{APd}}(m)}{\partial t}\right|_{\mathrm{act}}, \\
& \left.\frac{\partial f_{\mathrm{APa}}\left(m_{\mathrm{AP}}\right)}{\partial t}\right|_{\mathrm{act}},\left.\quad \frac{\partial g_{\mathrm{APa}}\left(m_{\mathrm{AP}}\right)}{\partial t}\right|_{\text {act }}
\end{aligned}
$$

in Eqs. (1)-(4), respectively, were evaluated for an aerosol of given size distribution and composition and for a given supersaturation $s_{v w}$, from the relations (see Pruppacher and Klett, 1978, p. 146):

$$
s_{v w}=\frac{A}{a}-\frac{B r_{N}{ }^{3}}{a^{3}-r_{N}{ }^{3}}
$$

with $A=\left(2 M_{w} \sigma_{w / a}\right) /\left(R T \rho_{w}\right), B=\left(\nu \Phi_{s} \in M_{w} \rho_{\mathrm{AP}}\right) /\left(M_{S} \rho_{w}\right)$; and

$$
\frac{\partial s_{v w}}{\partial a}=0=-\frac{A}{a^{2}}+\frac{3 B a^{2} r_{N}^{3}}{\left(a^{3}-r_{N}^{3}\right)^{2}} .
$$

Equations (19) and (20) determine $a_{c}$ and $r_{N c}$ through the relations

$$
\begin{aligned}
& a_{c}=-\frac{D}{2}+\left[\frac{D^{2}}{4}-E\right]^{1 / 2}, \\
& r_{N c}=\left[\frac{a_{c}^{3}\left(A-s_{v w} a_{c}\right)}{A+\left(B-s_{v w}\right) a_{c}}\right]^{1 / 3},
\end{aligned}
$$

with

$$
\begin{aligned}
& D=\frac{2 B^{2} A-6 B A s_{v w}}{3 B s_{v w}^{2}-3 B^{2} s_{v w}}, \\
& E=\frac{3 B A^{2}}{3 B s_{v w}^{2}-3 B^{2} s_{v w}},
\end{aligned}
$$

where $a_{c}$ is the critical radius for activation and $r_{N c}$ is the critical radius of a dry aerosol nucleus which can become activated to a drop at the given supersaturation. An evaporating drop was considered to become an aerosol particle when its size reached the value $a_{c}$ again.

Although it would be desirable to eventually evaluate Eqs. (1)-(4) in conjunction with a two-dimensional convective cloud model, we decided in the present study to test our scavenging framework in conjunction with a simple entraining air parcel. For this purpose, the first three terms on the right-hand side of Eqs. (1) and (3) and the first two terms on the right-hand side of Eqs. (3) and (4) were replaced by the terms $-\mu f_{\mathrm{d}}(m) U ;-\mu g_{\mathrm{APd}}(m) U ;-\mu\left[f_{\mathrm{APa}}\left(m_{\mathrm{AP}}\right)\right.$ $\left.-f_{\mathrm{APa}}^{\prime}\left(m_{\mathrm{AP}}\right)\right] U ;-\mu\left[g_{\mathrm{APa}}\left(m_{\mathrm{AP}}\right)-g_{\mathrm{APa}}^{\prime}\left(m_{\mathrm{AP}}\right)\right] U$, respectively.

In addition, the following relations were needed to form a closed set of equations for completely describing the conditions in the air parcel (see Pruppacher and Klett, 1978, p. 354-357):

$$
\frac{d T}{d t}=-\frac{\mathrm{g} U}{c_{p \mathrm{a}}}-\mu\left(T-T^{\prime}\right) U+\frac{L_{e}}{c_{p \mathrm{a}}} C_{\mathrm{Ph}},
$$

where

$$
\begin{gathered}
C_{\mathrm{Ph}}=\frac{d w_{L}^{*}}{d t}+\mu\left(w_{L}^{*}-w_{L}^{*}\right) U, \\
\frac{d w_{V}}{d t}=-\mu\left(w_{V}-w_{V}^{\prime}\right) U-C_{\mathrm{Ph}},
\end{gathered}
$$




$$
\begin{aligned}
& \frac{d U}{d t}=\frac{\mathrm{g}}{1+\gamma}\left[\frac{T_{V}-T_{V}^{\prime}}{T_{V}^{\prime}}-w_{L}^{*}\right]-\frac{\mu}{1+\gamma} U^{2} ; \quad \gamma=0.5, \\
& \frac{d \ln R}{d t}= \frac{1}{3}\left(\mu U-\frac{d \ln \rho_{\mathrm{a}}}{\mathrm{dt}}\right), \\
& \rho_{\mathrm{a}}=\frac{\mathrm{pM} \mathrm{a}}{\mathscr{R T}}, \\
& \frac{d \ln p}{d t}=-\frac{\mathrm{g} U M_{\mathrm{a}}}{R T}, \\
& \mu=\frac{0.6}{R}, \\
& s_{v w}=\frac{w_{V}}{w_{V \mathrm{sat}, w}}-1, \\
& w_{L}^{*}=w_{L}+w_{\mathrm{LAP}}= \int_{0}^{\infty} m f_{\mathrm{d}}(m)\left[1-Q_{\mathrm{APd}}(m)\right] d m \\
&+\int_{0}^{\infty} m_{\mathrm{AP}} f_{\mathrm{APa}}\left(m_{\mathrm{AP}}\right)\left[1-Q_{\mathrm{APa}}\left(m_{\mathrm{AP}}\right)\right] d m_{\mathrm{AP}} .
\end{aligned}
$$

The equations given above represent a closed system when $T^{\prime}, w_{v}^{\prime}, f_{\mathrm{APa}}^{\prime}, g_{\mathrm{APa}}^{\prime}$, as well as the aerosol particle composition, have been specified. Note that the primed quantities refer to the parcel's environment, and that the liquid water content $w^{*}$ is due to the liquid water content of the drops and the liquid water attached to the unactivated aerosol particles. In order to facilitate numerical computations, we also have expressed everywhere the mass of a particle in terms of the logarithm $(\mathrm{ln})$ of its radius.

\section{Cases chosen for evaluation}

The theoretical model described in Section 2 was numerically evaluated for the following cases.

\section{a. Case 1}

In case 1 it was assumed that the initial drop size spectrum was given and described by the relation

$$
f_{\mathrm{d}}(\ln a)=\sum_{i=1}^{2} \frac{N_{\mathrm{d}, i}}{(2 \pi)^{1 / 2} \sigma_{i}} \exp \left(\frac{\ln a-\mu_{i}}{2^{1 / 2} \sigma_{i}}\right)^{2},
$$

with $N_{\mathrm{d}, 1}=300 \mathrm{~cm}^{-3}, N_{\mathrm{d}, 2}=200 \mathrm{~cm}^{-3}, \mu_{1}=\ln (9$ $\left.\times 10^{-4}\right), \mu_{2}=\ln \left(11 \times 10^{-4}\right), \sigma_{1}=0.2, \sigma_{2}=0.3, w_{L}$ $=2.78 \mathrm{gm}^{-3}$. This drop size distribution was allowed to broaden by stochastic collision and coalescence in the manner described by Berry and Reinhardt (1974) and by Berry $(1974 \mathrm{a}, \mathrm{b}, \mathrm{c})$. The coalescence efficiency for drops was assumed to be unity, while the values for the collision efficiency of drops were assumed to be a combination of those given by Davis (1972), Jonas (1972), Klett and Davis (1973), Lin and Lee
(1975), and Schlamp et al. (1976), in a selection of values given by Hall (1980). While growing by collision and coalescence the drops were allowed to pick up aerosol particles from the air by impaction scavenging with an efficiency as given by Grover et al. (1977) and Wang et al. (1978). The dry aerosol particles were assumed to have a particle size distribution given by the relation

$$
f_{\mathrm{APa}}\left(\ln r_{N}\right)=10^{-14} r_{N}^{-3.5}
$$

In one evaluation of case 1 the scavenged aerosol particles were prohibited from being redistributed among the drop size categories due to collision and coalescence, while in the other evaluation of this case the scavenged particles were allowed to be redistributed.

\section{b. Case 2}

In Case 2 it was again assumed that the drop spectrum was given but in this case was described by the relation

$$
f_{\mathrm{d}}(\ln a)=3 N_{\mathrm{d}} \frac{(\nu+1)^{\nu+1}}{\Gamma(\nu+1)}\left[\frac{m}{\bar{m}}\right]^{\nu+1} \exp \left[-(\nu+1) \frac{m}{\bar{m}}\right],
$$

with $\nu=0, w_{L}=1 \mathrm{~g} \mathrm{~m}^{-3}$, and with the mean drop mass $\bar{m}$ given from the mean drop radius $\bar{a}=13 \mu \mathrm{m}$ and $9 \mu \mathrm{m}$, with $N_{\mathrm{d}}=108$ and 273 , respectively. These two drop size distributions were again allowed to broaden by a stochastic collision-coalescence process assuming the same coalescence and collision efficiencies for drops as those used for case 1. While growing by collision and coalescence the drops were allowed to capture aerosol particles from the air by impaction scavenging with an efficiency given by Grover et al. (1977) and Wang et al. (1978). The aerosol particles were assumed to follow the size distribution Eq. (33). The scavenged aerosol mass was then allowed to be redistributed among the drop size categories as a result of collision and coalescence between the drops.

\section{c. Case 3}

Unlike case 1 and case 2 , in which the initial drop size distribution was assumed, the drop size distribution in case 3 was computed assuming that the spectrum was controlled by nucleation, condensation, and collision and coalescence. For this purpose the parcel condensation model of Lee et al. (1980) and of Lee and Pruppacher (1977) was coupled with our collision-coalescence model structured after Berry and Reinhardt (1974) and Berry (1974a,b,c). While being activated to drops, aerosol particles were allowed to be consumed by nucleation scavenging. In addition, each drop was allowed to pick up aerosol particles by impaction scavenging with an efficiency as given by Grover et al. (1977) and Wang et al. (1978). During 
growth of the drops by collision and coalescence the aerosol mass, scavenged by these two mechanisms, was then allowed to be redistributed among the various drop size categories.

A modified gamma distribution of the form described by Deirmendjian (1969) was used to describe: the size distribution of the aerosol particles subjected. to nucleation and impaction scavenging:

$$
f_{\mathrm{APa}}\left(\ln r_{N}\right)=\mathrm{Ar}_{N}^{\alpha+1} \exp \left(-B r_{N}^{\gamma}\right)
$$

with $A=4.9759 \times 10^{7} \mathrm{~cm}^{-3} \mu \mathrm{m}^{-3}, B=15.1186$ $\mu \mathrm{m}^{-0.5}, \alpha=2, \gamma=0.5$. In case 3 the aerosol size distribution was assumed to be a continental type with a total number concentration $N_{a}=1000 \mathrm{~cm}^{-3}$, and a composition $\epsilon=m_{s} m_{N}{ }^{-1}=1.0$; the soluble portion of the aerosol was assumed to consist of ammonium sulfate $\left(\mathrm{NH}_{4}\right)_{2} \mathrm{SO}_{4}$ with a molecular weight. of $M_{s}=132$. The quantities $D_{v}, M_{w}, e_{\text {sat, } w}$, $\Phi_{s}, \sigma_{w / \mathrm{a}}, \nu_{\mathrm{a}}, k_{\mathrm{a}}, \rho_{\mathrm{a}}, c_{p \mathrm{a}}, \alpha_{T}, \alpha_{c}, \Delta_{v}, \Delta_{T}, L_{e}, F_{v}$ were assumed to have the values given by Pruppacher and Klett (1978). The temperature and humidity distribution assumed in the present case was that used by Lee et al. (1980) in their computations. The initial updraft radius was assumed to be 350 meters, and the initial updraft speed was assumed to be $1 \mathrm{~m} \mathrm{~s}^{-1}$.

\section{d. Case 4}

The conditions used in case 4 were the same as those in case 3, except that the aerosol material was assumied to have a composition $\epsilon=0.01$, with the water insoluble portion to consist of silicate.

\section{e. Case 5}

The conditions used in case 5 were the same as those in case 3, except that a maritime-type aerosol was considered with $N_{\mathrm{a}}=100 \mathrm{~cm}^{-3}$ and $\epsilon=1$, and for $A=5.333 \times 10^{4} \mathrm{~cm}^{-3} \mu \mathrm{m}^{-2}, B=8.9443 \mu \mathrm{m}^{-0.5}$, $\alpha=1, \gamma=0.5$ in the aerosol size distribution (Eq. (35)).

In cases 1 and 2 we assumed that the aerosol particles scavenged by the drops through impaction scavenging were dry. In cases 3 to 5 two conditions were compared with each other as follows.

Under the first condition (continuous lines in Figs. $3 \mathrm{~d}, \mathrm{e}, 4 \mathrm{~d}$ e, $5 \mathrm{~d}$, e) the aerosol particles scavenged through nucleation scavenging were assumed to be initially dry, and those particles that did not become activated to drops, but were allowed to be scavenged by impaction scavenging, were assumed to remain dry during the whole scavenging process.

Under the second condition (dashed lines in Figs. $3 \mathrm{~d}, \mathrm{e}, 4 \mathrm{~d}, \mathrm{e}, 5 \mathrm{~d}, \mathrm{e})$ the aerosol particles scavenged through nucleation scavenging were assumed to be initially in equilibrium with humid air of $99 \%$ relative humidity. Those particles that did not become activated to drops but were exposed to impaction scav- enging were also allowed to grow according to the humidity in the parcel.

All five cases were evaluated with the help of Eqs. (1)-(31), using numerical procedures outlined in Hall (1980), Smolarkiewicz (1983) and in Flossmann (1985).

\section{Results and discussion}

The results of our computations are displayed graphically in Figs. 1-5, where five cases were distinguished. The results of case 1 are illustrated by Figs. la-c. The time evolution of the drop size distribution specified in Section 3 is shown in Fig. 1a in time intervals of 50 seconds during which the drops were allowed to grow by collision and coalescence. The growth behavior is expressed in terms of the mass distribution function $g_{w}$ which is plotted against the drop radius. We notice from this figure that the drop size distribution broadens relatively rapidly, so that in approximately seven minutes the main water mass has become associated with precipitation size drops of radii between 100 and $1000 \mu \mathrm{m}$. Although these drops comprise the main water mass of the cloud, the main number concentration of drops still remains "left behind" in the radius interval 5-30 $\mu \mathrm{m}$. In Fig. $1 \mathrm{~b}$ the mass distribution function $g_{\mathrm{APd}}$ for the aerosol particle mass inside the drops is plotted against the drop radius for the entire collisional evolution of the drop size spectrum, during which the drops were allowed to capture by impaction scavenging the aerosol particles of the size distribution specified in Section 3. For obtaining the results plotted in Fig. $1 \mathrm{~b}$ we purposely made the incorrect assumption that the captured aerosol mass would not become affected by the collision and coalescence which takes place among the growing drops, i.e., it was assumed that the amount of aerosol material, which a given drop size category contains, is solely the result of the amount of aerosol material which the drops of this size category captured from the air by itself. We note from Fig. $1 \mathrm{~b}$ that under these conditions, during the whole growth period of 400 seconds, the main aerosol mass is contained inside drops which belong to the small size end of the drop size distribution, i.e., inside drops of nonprecipitating size, despite the fact that during this time period the main water mass of the drop size distribution continuously shifted to increasingly larger drop sizes.

If, however, the aerosol mass added to each drop size category by impaction scavenging is allowed to be affected by the collision-coalescence process a completely different result emerges. This result is illustrated in Fig. 1c in which again the mass distribution function $g_{\mathrm{APd}}$ for aerosol particles is plotted as a function of drop radius. We notice from this figure that as a result of the collision-coalescence process the aerosol particle mass scavenged from the 

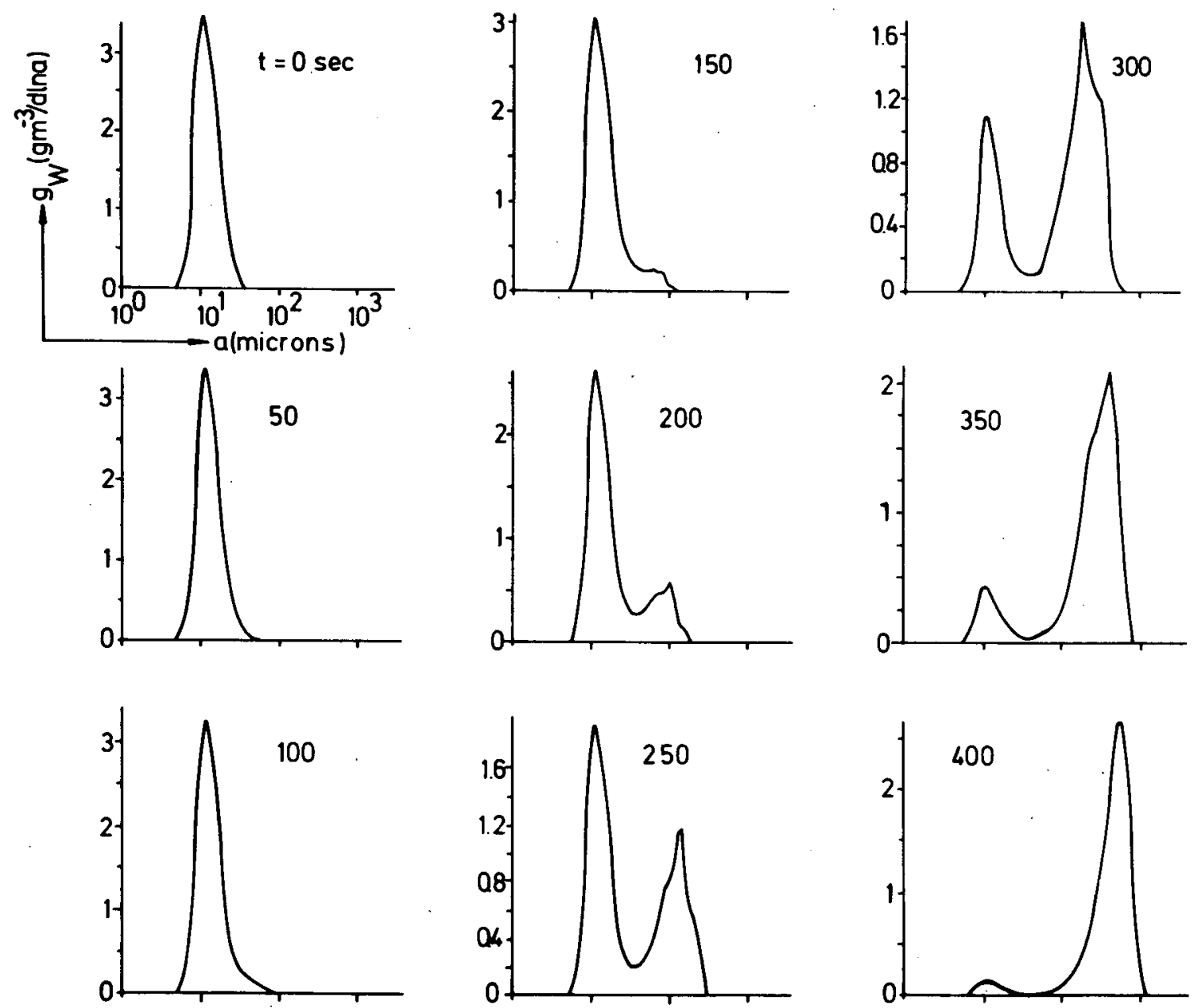

FIG. 1a. Case 1. Time evolution of the drop mass distribution function $g_{w}$ as a function of drop radius $\alpha$ for an assumed initial drop size spectrum [Eq. (32)] of initial total drop concentration $N_{d}=500 \mathrm{~cm}^{-3}$ and of a constant liquid water content $w_{L}=2.78 \mathrm{gm}^{-3}$. Aerosol particle size distribution given by Eq. (33). Note the changing ordinate scale.

air by impaction becomes redistributed among the drop size categories. Thus, we note that as the main water mass becomes shifted to larger drop sizes the main aerosol particle mass becomes shifted along with the main water mass so that after about seven minutes the main aerosol particle mass is completely inside the main cloud water mass, i.e., inside drops of precipitation size. The result is not quite trivial as the number of precipitation drops is only a very small fraction of the total number of cloud drops present. One therefore could have expected that the main aerosol mass would be associated with the large number of nonprecipitating drops rather than the few precipitating ones.

The present results of Figs. 1a-c emphasize that a correct description of the aerosol particle removal mechanism not only must include a correct description of the intake by the drops of aerosol particles from the air but also a correct description of the redistribution of this aerosol particle mass as a result of the stochastic collision-coalescence process among the drops. If such a correct description is used, one finds that the main aerosol mass always is closely associated with the main water mass in a cloud, thus insuring that if a cloud reaches the precipitation stage the main aerosol mass will become returned to the ground with the main water mass of the cloud.

The results of case 2 are displayed in Figs. 2a-d. The time evolution of the mass distribution function $g_{w}$ for the drops for the two initial size distributions specified in Section 3 has been plotted together with the associated time evolution of the mass distribution function $g_{\text {APd }}$ for the aerosol particles captured from air by impaction scavenging, and redistributed among the drop size categories as a result of collision and coalescence of the drops. In contrast to Figs. 1a-c the time evolutions have been plotted in three-dimensional form with the scale of the ordinate remaining 

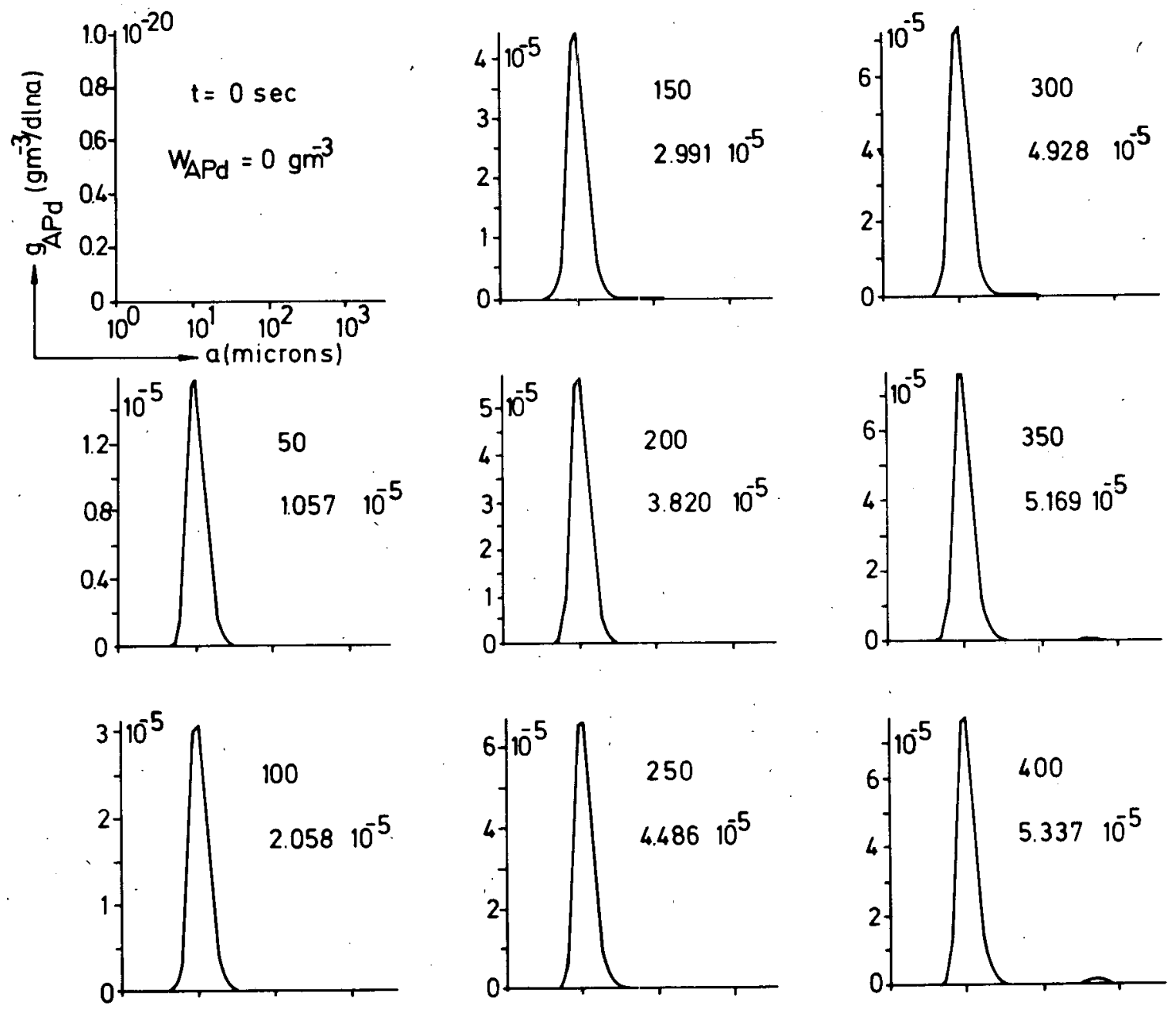

FIG. 1b. Case 1. Time evolution of the mass distribution function $g_{\mathrm{APd}}$ and total particle mass $w_{\mathrm{APd}}$ inside the radius $\alpha$. Aerosol particles captured by impaction scavenging by drops of size spectrum evolving in time as given in Fig. la. No redistribution of aerosol particle mass due to collision and coalescence is allowed. Note the changing ordinate scale.

the same at all times. We note from Figs. 2a-b for a drop size distribution with $\bar{a}=13 \mu \mathrm{m}$ that precipitation size drops are formed relatively quickly. Correspondingly, the main aerosol particle mass is also carried quickly into the cloud water composed of precipitation size drops. For the drop spectrum with $\bar{a}=9 \mu \mathrm{m}$ we note from Figs. $2 \mathrm{c}$ and $2 \mathrm{~d}$ that, as expected, it takes considerably longer to develop precipitation size drops. The shift of the main aerosol mass also takes correspondingly longer and the total amount of the aerosol mass scavenged is comparatively lower due to the dependence of the collection efficiency on drop and aerosol particle radius. The sequence $2 a-d$ illustrates again the manner in which the captured aerosol particle mass is affected by redistribution of cloud drops following collision and coalescence and how this redistribution is significantly controlled by the original size spectrum of the cloud drops.
The results of case 3 are displayed in Figs. 3a-f. Figures $3 a, b$ give the time evolution of drop size distribution in intervals of 200 seconds. Drops are formed by condensation on the aerosol particle size distribution specified in Section 3 and subsequently grow by collision and coalescence. This size evolution is documented by the number distribution function $f_{\mathrm{d}}$ as a function of drop radius in Fig. 3a, and by the mass size distribution $g_{w}$ as a function of drop radius in Fig. 3b. We note from Figs. 3a, b that the drop size distribution on the continental aerosol of composition $\epsilon=1.0$ broadens only a little and does not form precipitation size drops. Therefore, we expect from the results of Figs. 1 and 2 that the main aerosol mass remains contained in drops of non-precipitating size. This is indeed verified by the results shown in Fig. 3c. As a consequence of this, the main aerosol mass will not be returned to the ground. Considering the total aerosol particle mass in the cloud water per 

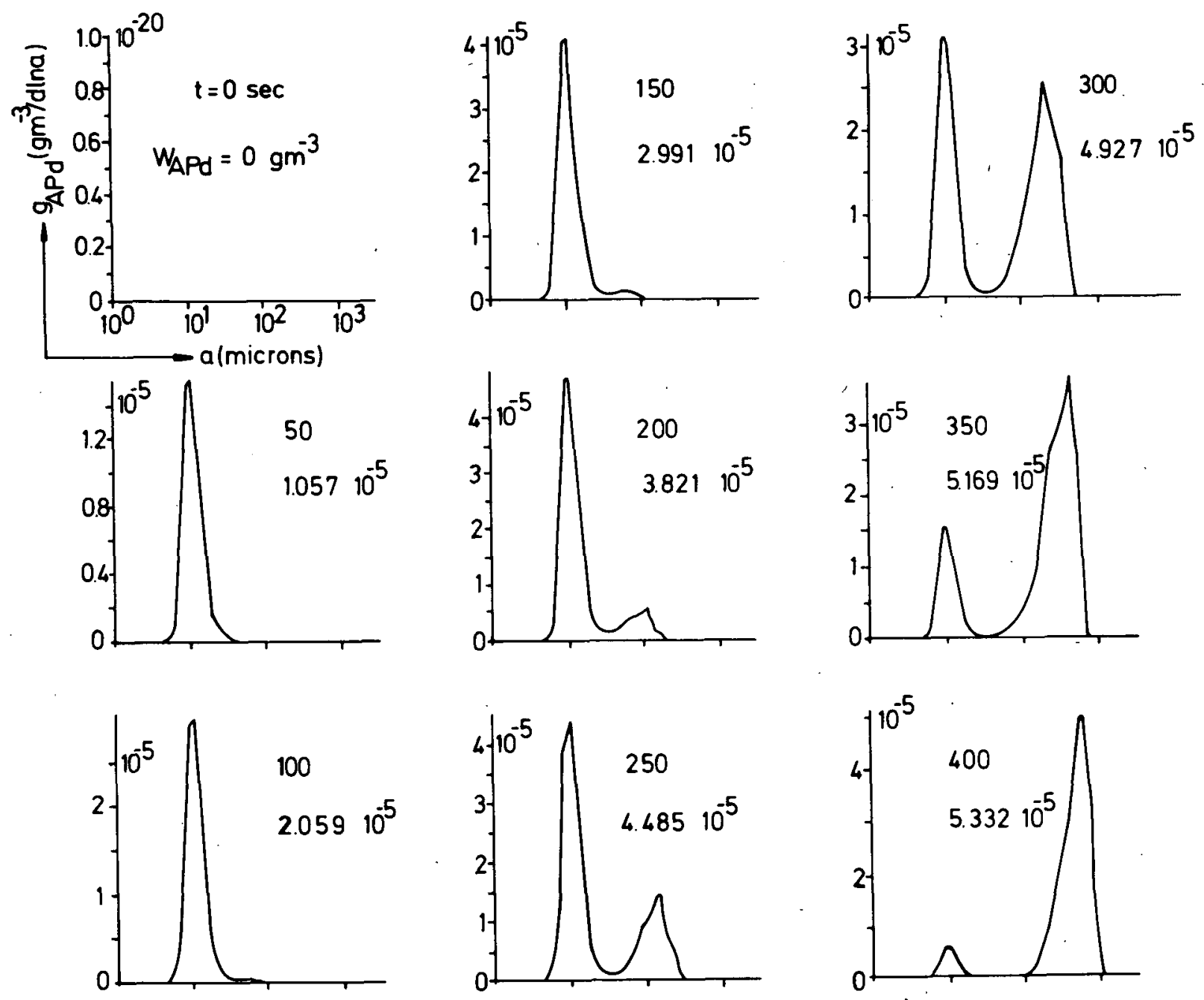

FIG. 1c. Case 1. As in Fig. Ib except that a redistribution of the scavenged aerosol particle mass due to collision and coalescence is allowed.

kilogram dry air $w_{\text {APd }}$ we note further from Fig. $3 \mathrm{c}$ that the main aerosol particle mass is captured during the drop nucleation stage at the beginning of the air parcel's lifetime, while at later times the total amount of captured aerosol particle mass increases only very little with time as a result of continued nucleation of aerosol particles transported into the parcel by entrainment, impaction scavenging of the aerosol particles left unactivated during condensation and detrainment of drops. In Figs. 3d, e the aerosol mass distribution function $g_{\mathrm{APa}}$ and the aerosol number distribution function $f_{\mathrm{APa}}$ for the aerosol particle left uncaptured in air have been plotted as a function of the particle radius. We note from these figures that the uptake of aerosol particles by drops through nucleation and impaction scavenging causes a corresponding disappearance of aerosol particles in air. As suggested from Fig. $3 \mathrm{c}$ this disappearance of aerosol particles is most pronounced during the condensation stage, leaving in the air aerosol particles of a size distribution which is truncated at the large size end of the particle distribution. This size distribution remainder represents the "drop-interstitial-aerosol" which in comparison to the original aerosol distribution is considerably reduced in number and mass. In fact, we note from Fig. 3d that the total number concentration of aerosol particles in air has become reduced by about $76 \%$ during the nucleation stage, while the mass has become reduced by several orders of magnitude. This truncation is very sharp in our computational case since we assumed that all aerosol particles have the same composition. Under atmospheric conditions a less sharp cutoff is expected due to the heterogeneous composition of natural aerosols. We further note that the total number of aerosol particles in air $N_{a}$ and the corresponding total aerosol particle mass in air per kilogram air $w_{\mathrm{APa}}$ continues after $t=400$ seconds to slightly decrease in time due 

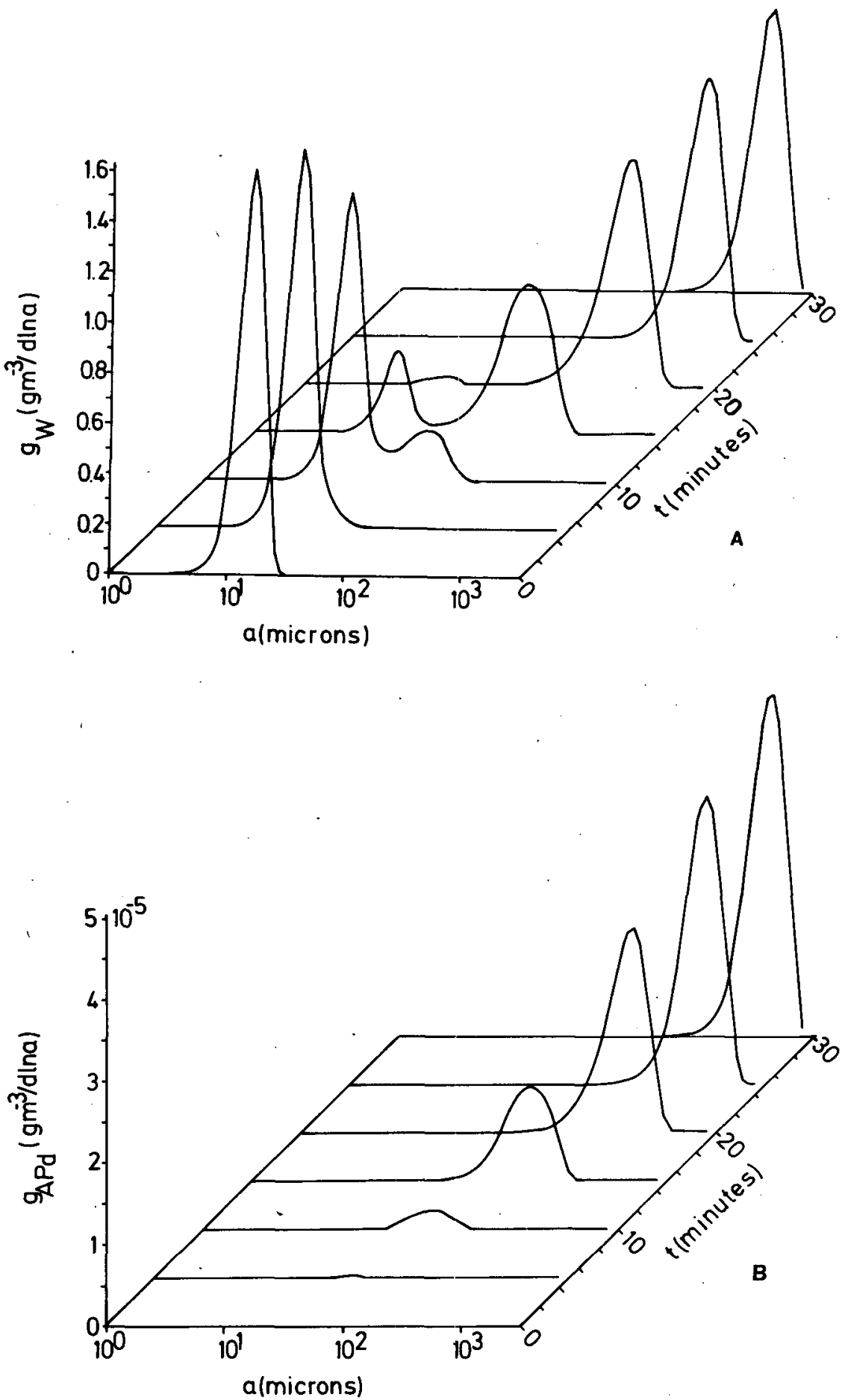

FIG. 2. (a) Case 2. Three-dimensional display of the time evolution of the drop mass distribution function $g_{w}$ as a function of drop radius $\alpha$ for an assumed initial total drop size spectrum [Eq. (34)] with $\bar{a}=13 \mu \mathrm{m}$, an initial total drop concentration $N_{d}=108 \mathrm{~cm}^{-3}$, and a constant liquid water content $w_{L}=1 \mathrm{gm}^{-3}$. Aerosol size distribution given by Eq. (33). (b) Case 2. Three-dimensional display of the time evolution of the aerosol particle mass distribution function $g_{\text {APd }}$ for aerosol particle mass inside drops of radius $\alpha$. Aerosol particles captured by impaction scavenging by drops of size spectrum evolving in time as given in (a). Scavenged aerosol mass is allowed to be redistributed. (c) Case 2. As in (a), except that $\bar{a}=9 \mu \mathrm{m}$ and the initial total drop concentration $N_{d}=237 \mathrm{~cm}^{-3}$. (d) Case 2. As in (b), but for a drop size spectrum evolving in time as given in (c). 

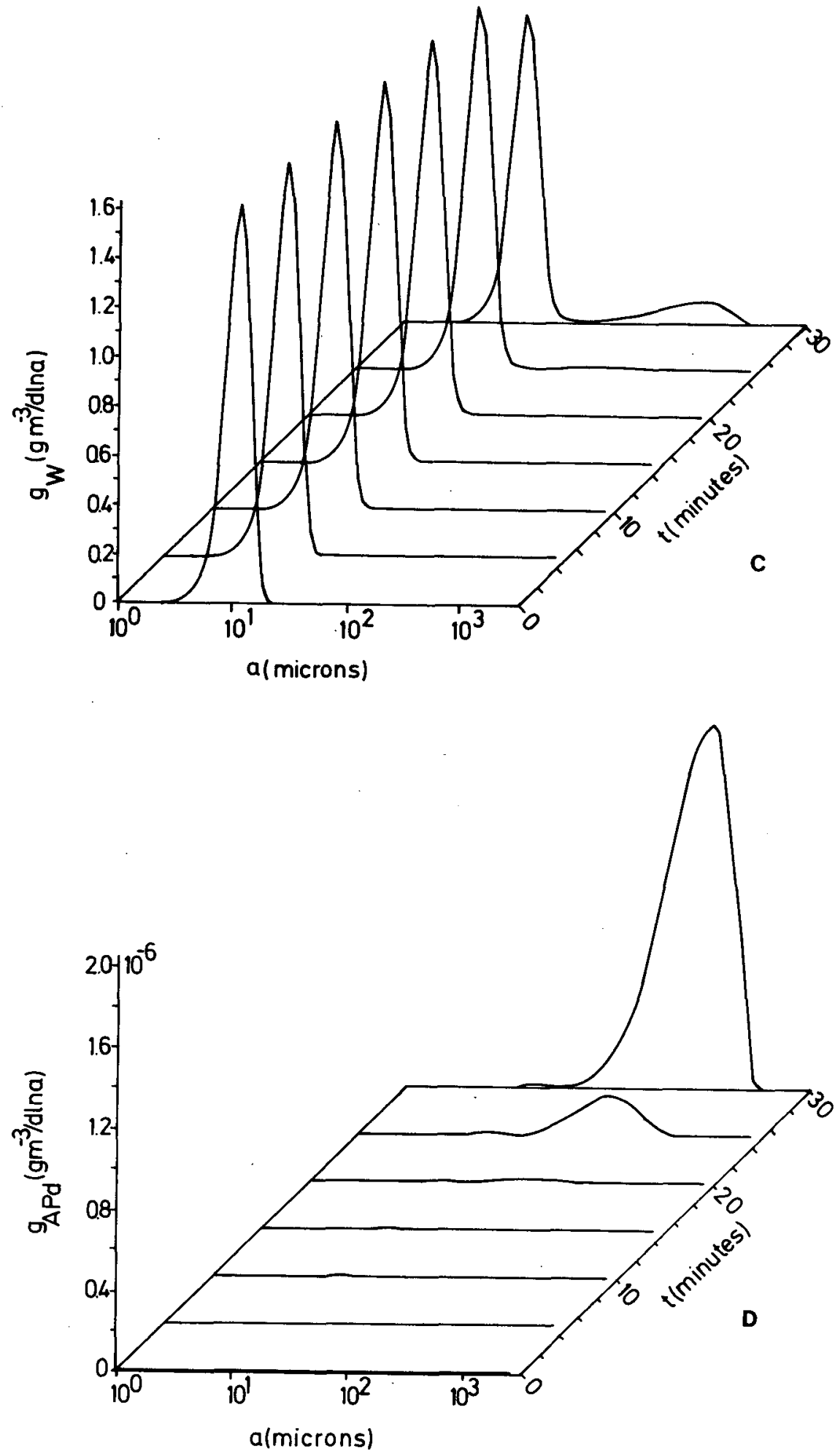

FIG. 2. (Continued)

to impaction scavenging. During this time the supersaturation remains practically unchanged. After $t$ $=1400$ seconds, however, $N_{\mathrm{a}}$ increases again due to a lowering of $s_{v w}$ on account of the entrained air which increases in dryness with height. Consequently, fewer aerosol particles become activated, i.e., more 

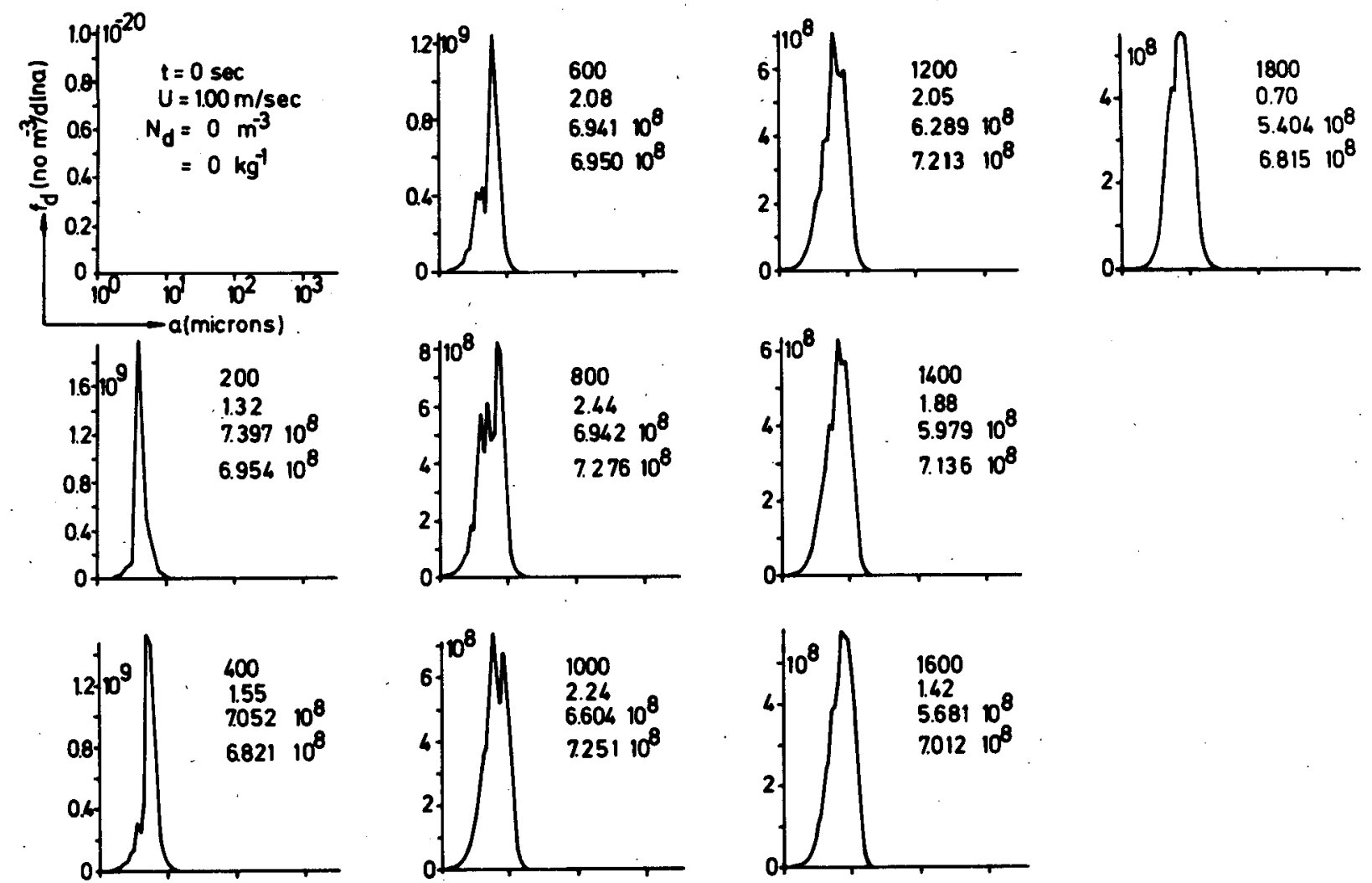

Fig. 3a. Case 3. Time evolution of drop number distribution function $f_{d}$ as a function of drop radius for an assumed initial size distribution of aerosol particles [Eq. (35)] of composition $\epsilon=1.0,\left(\mathrm{NH}_{4}\right)_{2} \mathrm{SO}_{4}$, and of initial concentration $N_{\mathrm{a}}=10^{3} \mathrm{~cm}^{-3}, \mathrm{growing}$ by condensation and collision-coalescence in an atmosphere of assumed vertical temperature and humidity distribution.
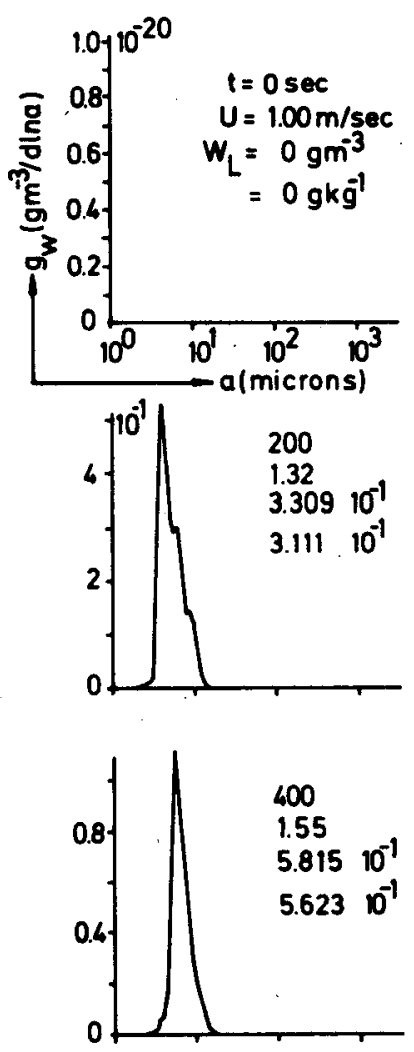
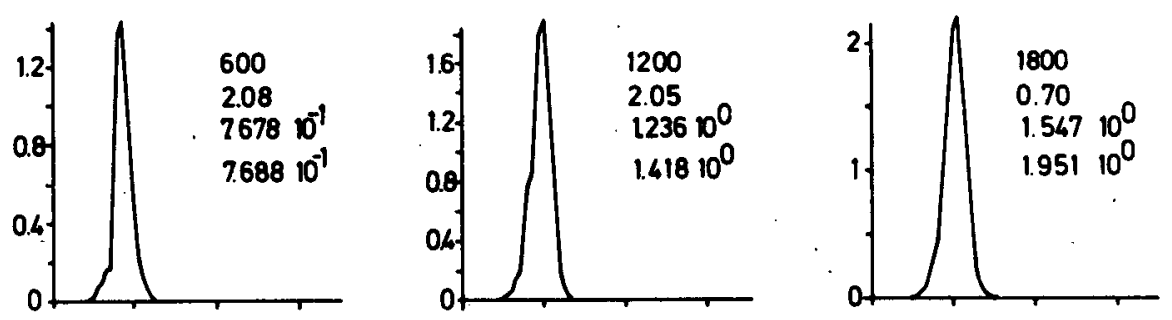
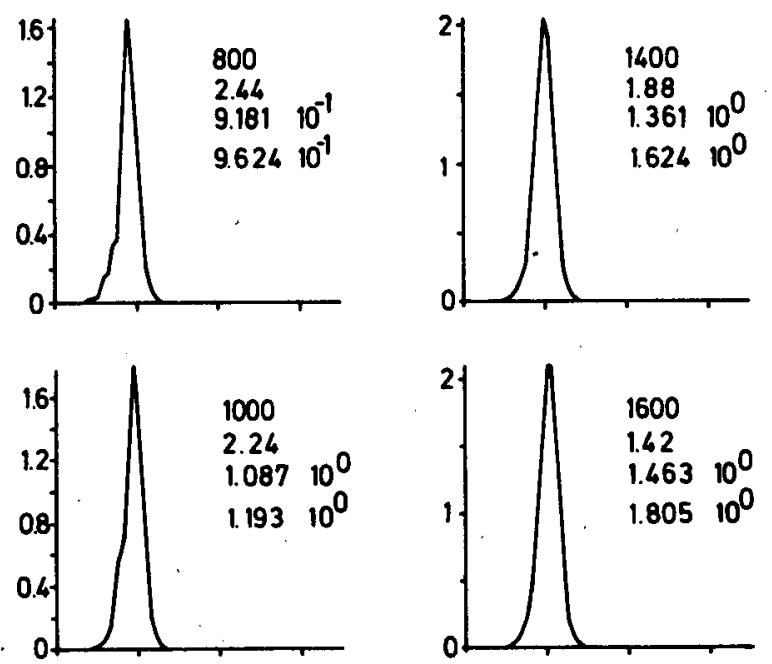

Fig. 3b. Case 3. Time evolution of drop mass distribution function $g_{w}$ as a function of drop radius for the conditions specified in Fig. 3a. 

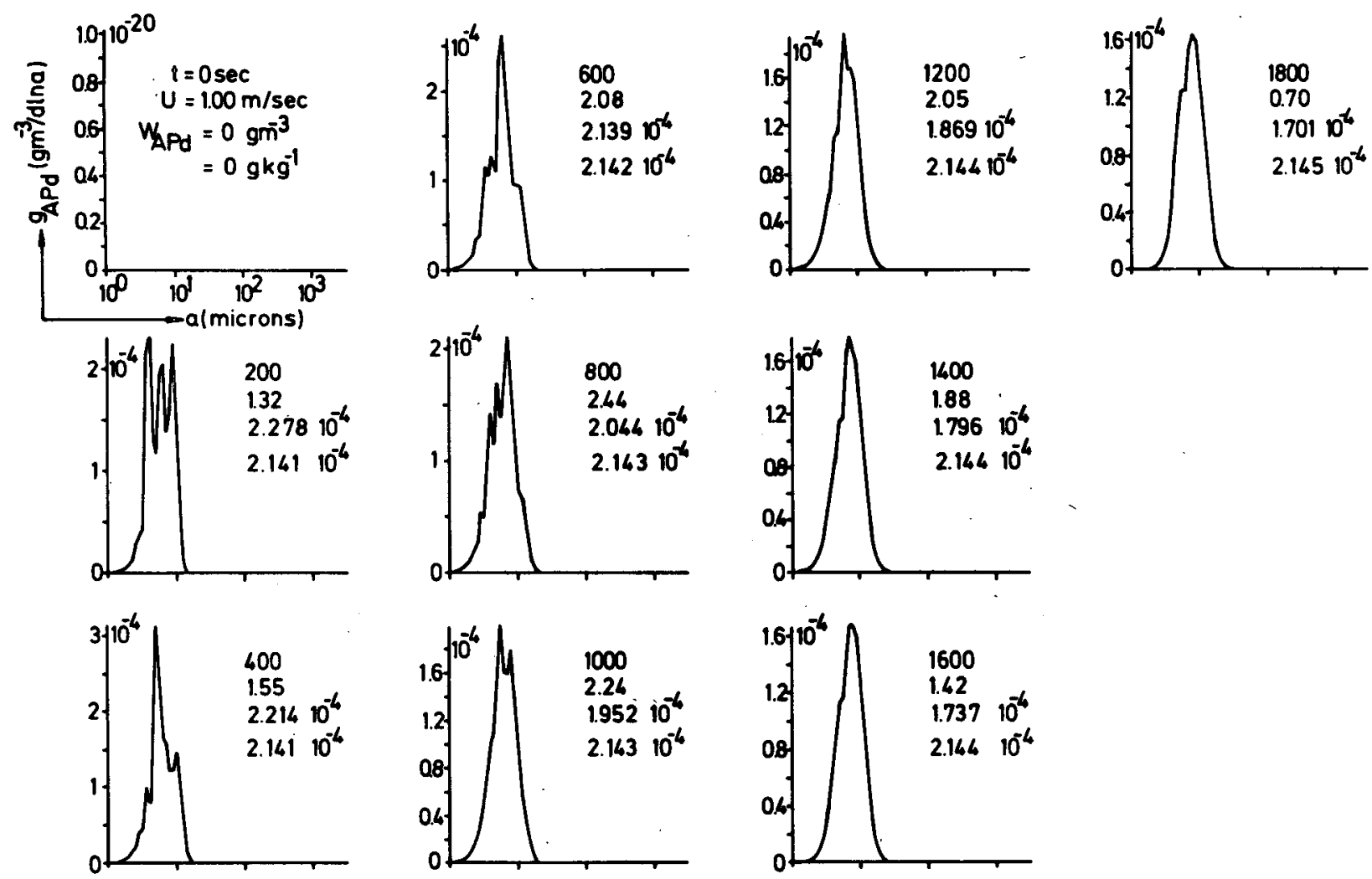

Fig. 3c. Case 3. Time evolution of aerosol particle mass distribution function $g_{\text {APd }}$ for aerosol mass inside drops of radius $\alpha$, captured through nucleation and impaction scavenging by drops of size spectrum evolving in time as given in Figs. 3a, b. Aerosol particle mass is allowed to be redistributed inside cloud water due to collision and coalescence of drops.

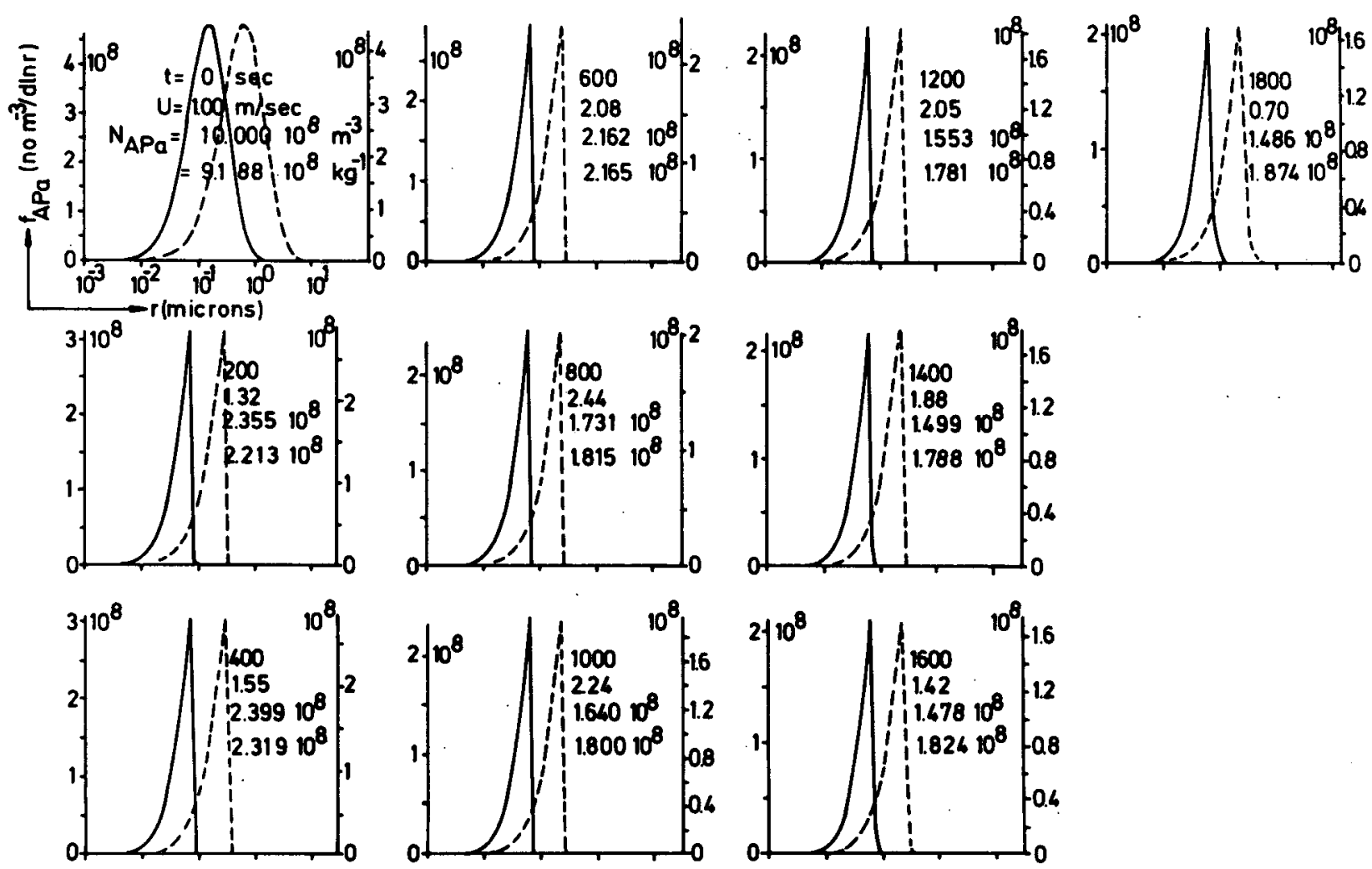

FIG. 3d. Case 3. Time evolution of aerosol particle number distribution function $f_{\mathrm{APa}}$ for aerosol particles of radius $r$ in air between cloud drops (interstitial aerosol) for the conditions specified in Fig. 3a. Continuous line (pertaining to ordinate on left): unactivated aerosol assumed to be dry; dashed line (pertaining to ordinate on right): unactivated aerosol allowed to grow with humidity. 

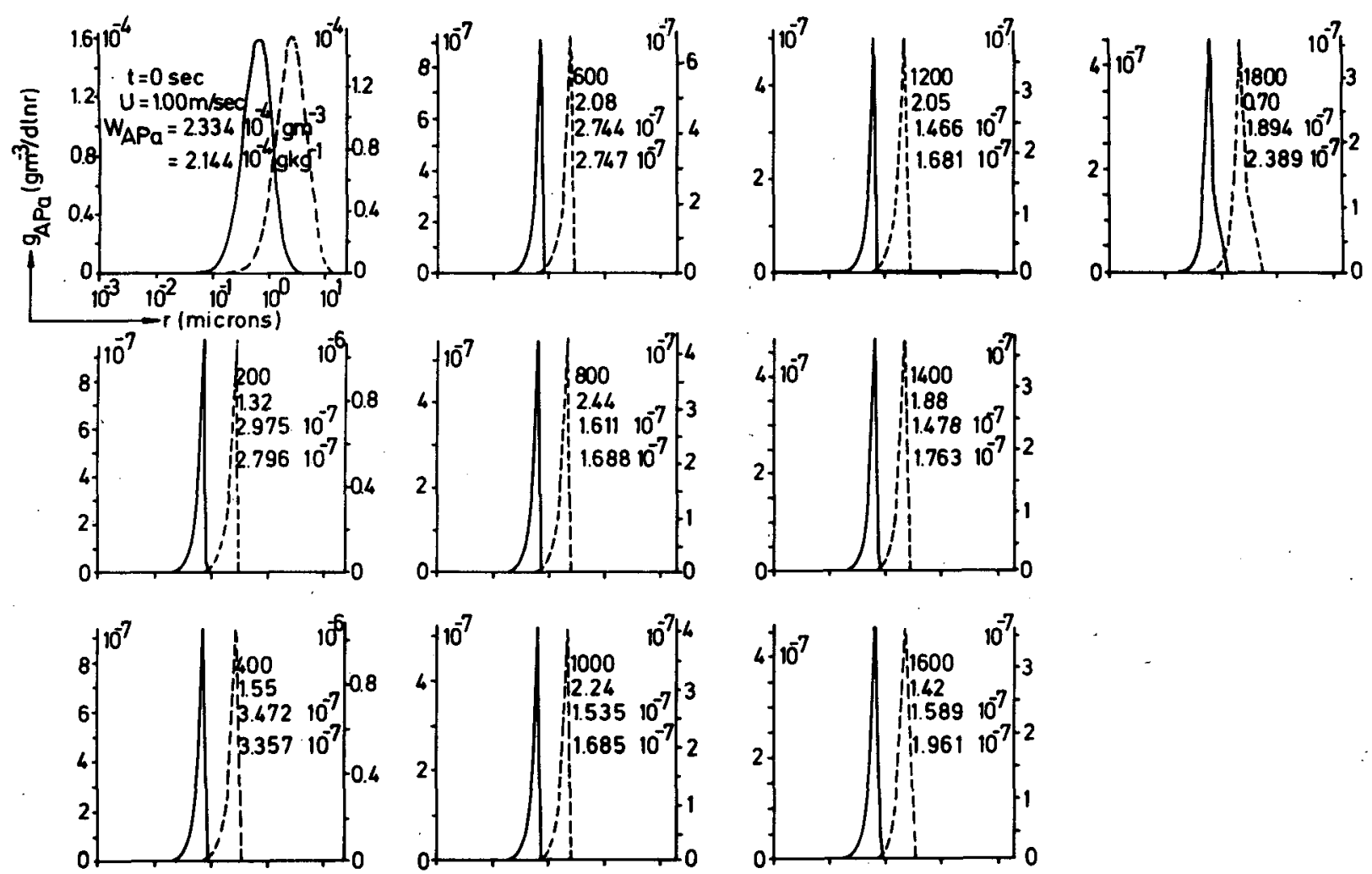

FIG. 3e. Case 3. Time evolution aerosol particle mass distribution $g_{\mathrm{APa}}$ for aerosol mass in air between cloud drops (interstitial aerosol) as a function of radius $r$ of aerosol particle for conditions specified in Fig. 3a. Continuous line (pertaining to ordinate on left): unactivated aerosol assumed to be dry; dashed line (pertaining to ordinate on right): unactivated aerosol allowed to grow with humidity.
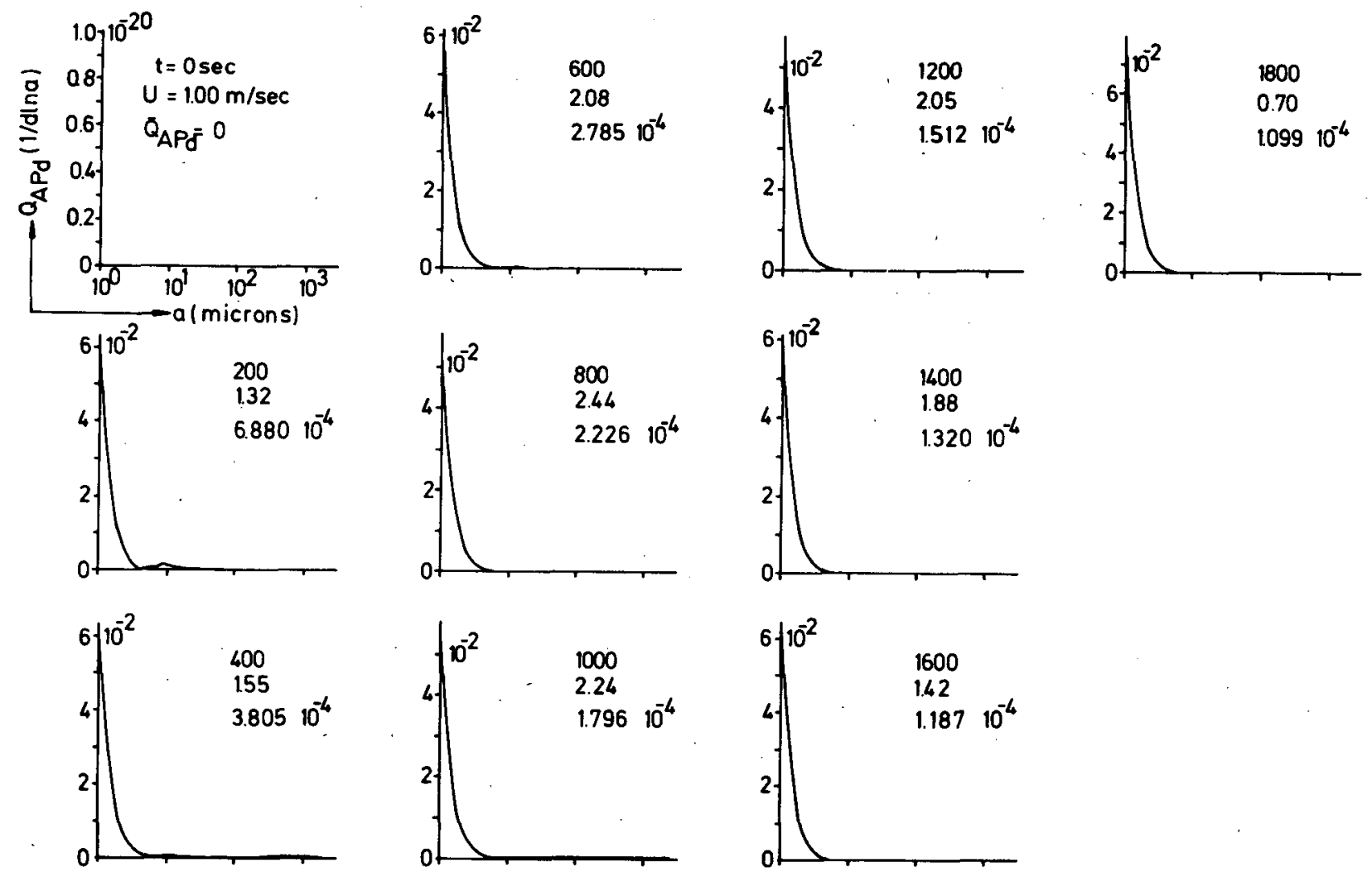

FIG. 3f. Case 3. Time evolution of aerosol particle mass mixing ratio $Q_{\text {APd }}$ in cloud drops as a function of drop radius for the conditions specified in Fig. 3a. 
remain as interstitial aerosol. Figure $3 f$ illustrates the time evolution of the mixing ratio $Q_{\mathrm{APd}}$, which is the ratio of aerosol mass to cloud drop mass, as a function of drop radius. We note that this mixing ratio strongly increases with decreasing drop size, implying that the smallest drops are also the most contaminated. However, we have to recall that the mass associated with the aerosol particles in these small drops is very small indeed. Thus, although the large drops are characterized by very small values of $Q_{\text {APd, }}$, they still carry the main aerosol mass. We also note from Fig. 3f that the total mass mixing ratio $\bar{Q}_{\text {APd }}$ of aerosol particle mass in the cloud water decreases with time as a result of continued "dilution" of the captured aerosol material due to the diffusion growth of the drops. If the unactivated aerosol is considered to be "dry" all the time, the results are as given by the continuous line in Figs. 3a-f. If, on the other hand, the unactivated aerosol particles are assumed to grow and reach a size at which they are in equilibrium with moist air in the cloud, the results given by the dashed line are found. We note that the functions $f_{\mathrm{d}}, g_{w}, g_{\mathrm{APd}}$ and $Q_{\mathrm{APd}}$ differ only insignificantly from the dry aerosol case so that the dashed and continuous lines would practically lie on top of each other. However, significant differences between the dry and moist cases are found for the functions $f_{\mathrm{APa}}$ and $g_{\mathrm{APa}}$ given in Figs. $3 \mathrm{~d}$, e. As expected, the number and mass size distribution of the moist interstitial aerosol is now shifted to larger sizes, shifting also the cutoff separating the activated from the unactivated aerosol particles. Also the total number concentration of interstitial aerosol particles is somewhat lower. The trend with time, however, is the same; therefore, in order to conserve space these numbers are not shown.

The results of case 4 are displayed in Figs. 4a-f. These figures illustrate the behavior of the same variables as those given in Figs. 3a-f, except that the behavior shown applies to a continental aerosol of $\epsilon$ $=0.01$, as specified in Section 3. Thus, we note from Figs. $4 a, b$ that the drop size spectrum which develops from this aerosol particle spectrum broadens relatively quickly and, in contrast to the aerosol particles of $\epsilon$ $=1.0$ assumed for case 3 , produces precipitation size drops within about 23 minutes. Correspondingly, the main aerosol mass contained in the cloud water also "reaches" precipitation size drops within this short time, as seen from Fig. $4 \mathrm{c}$. We further note that the total aerosol mass $w_{\text {APd }}$ in $\mathrm{g} \mathrm{kg}^{-1}$ contained in the cloud water continues to increase with time, although this increase is much smaller in comparison to the initial increase during the condensation period. The variation of the aerosol particle number and mass concentration in air is illustrated in Figs. 4d, e. Note that during the initial condensation stage the number concentration of the aerosol particles in air decreases by about $48 \%$. Unfortunately, however, the present data do not allow any conclusion concerning the effects of impaction scavenging on the total amount of material scavenged, as these effects are completely overpowered by the effects of nucleation scavenging. The time variation of the mixing ratio of the aerosol particle mass in the cloud water is given in Fig. $4 f$ which exhibits a similar rapid increase with decreasing drop size.

The results of case 5 are displayed in Figs. 5a-f. In this case a maritime aerosol of $\epsilon=1.0$ of size distribution specified in Section 3 was assumed. We note from Figs. 5a, b that in this case the drop size distribution broadens even faster, leading to precipitation size drops within about 17 minutes. Figure 5c shows the expected corresponding rapid redistribution of the main aerosol mass entering the precipitation size drops within the same short time. We also note the continued but small increase of the aerosol mass $w_{\text {APd }}$ in cloud water as time proceeds. The corresponding loss of aerosol particle number and mass concentration is displayed in Figs. 5d, e. In this case the decrease in the number concentration of aerosol particles during the condensation stage amounts to $94 \%$. The time variation of the mixing ratio of the aerosol particle mass in the cloud water is given in Fig. $5 f$ with the same features as those in Figs. 3f and $4 f$.

The multiple peaks in the drop size distribution $f_{\mathrm{d}}$ (and, correspondingly, in the mass distribution of the aerosol in the cloud water $g_{\mathrm{APd}}$ ) are somewhat unexpected. Previous studies on condensation with models allowing entrainment (Warner, 1973; Mason and Jonas, 1974; Lee and Pruppacher, 1977, and Lee et al., 1980) show that entrainment of nuclei leads to the development of two modes in the drop size distribution, and a third mode representing the pool of the unactivated aerosol particles. Such a double maximum in the drop size spectrum is indeed frequently found in atmospheric clouds (see, e.g., Pruppacher and Klett, 1978). It is our opinion that this agreement is due to an artificiality, namely, that in the previous models the term describing the entrained nuclei does not contain the requirement that the entrained nuclei must be activated before they can grow by diffusion. Rather, in previous models all the nuclei entrained were treated as activated and allowed to grow upon entry into the cloud. If, however, the requirement of activation before growth is imposed also on the entrained nuclei, then multiple peaks appear as long as (as in previous condensation models) all aerosol particles treated by the model have the same composition, and as long as (as in most previous condensation models) the drops formed by condensation are not allowed to mix by turbulent motions in the cloud. The constraint of activation on the entrained nuclei has as a consequence that new drops only appear after a critical time has elapsed, a time after which the vapor pressure again is large enough to raise the supersaturation in the parcel above that required for activating aerosol particles to drops. 

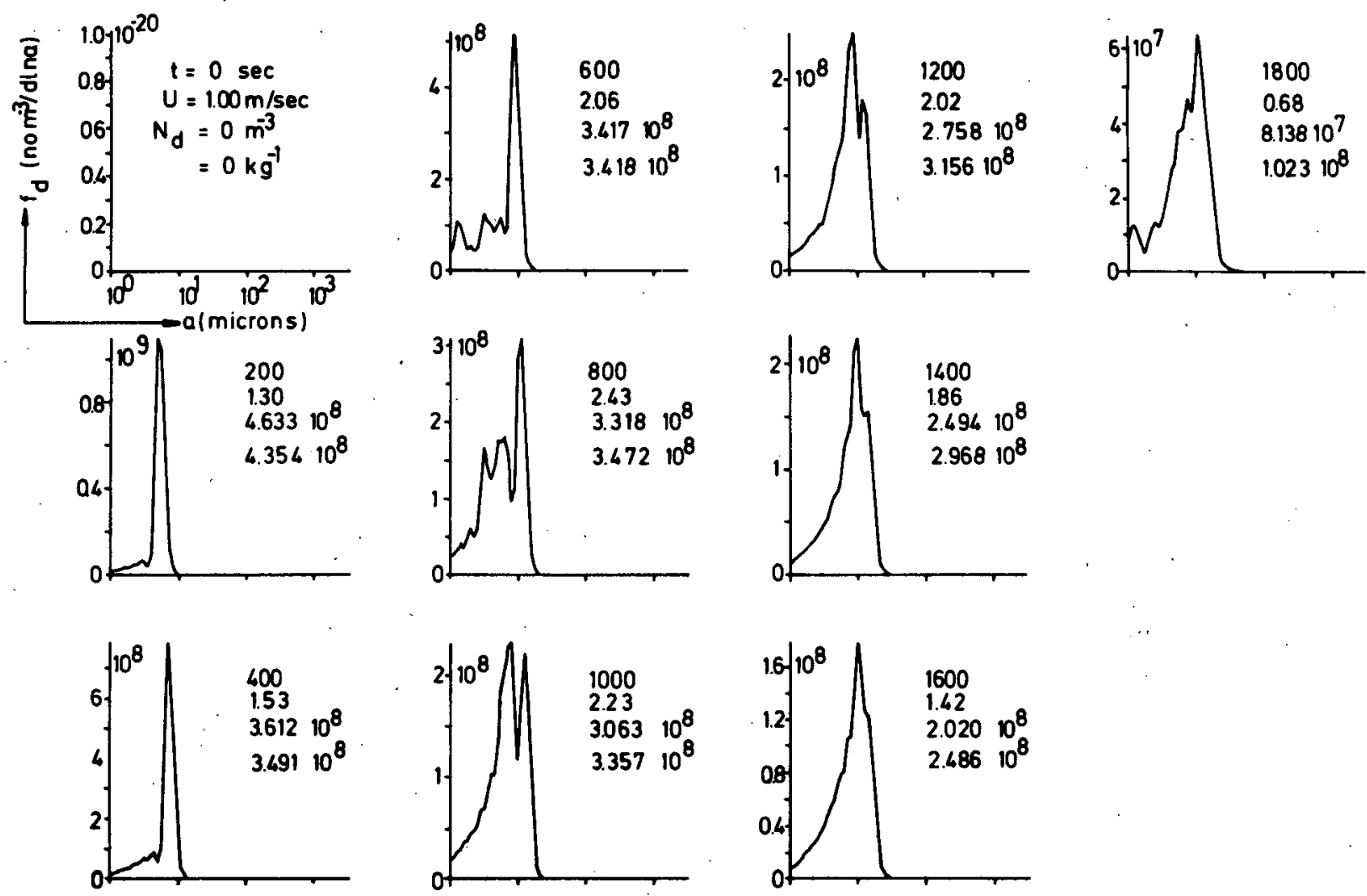

Fig. 4a. Case 4. As in Fig. 3a, but for $\epsilon=0.01$, with mixed aerosol particles being composed of $1 \%\left(\mathrm{NH}_{4}\right)_{2} \mathrm{SO}_{4}$ and $99 \%$ insoluble material.
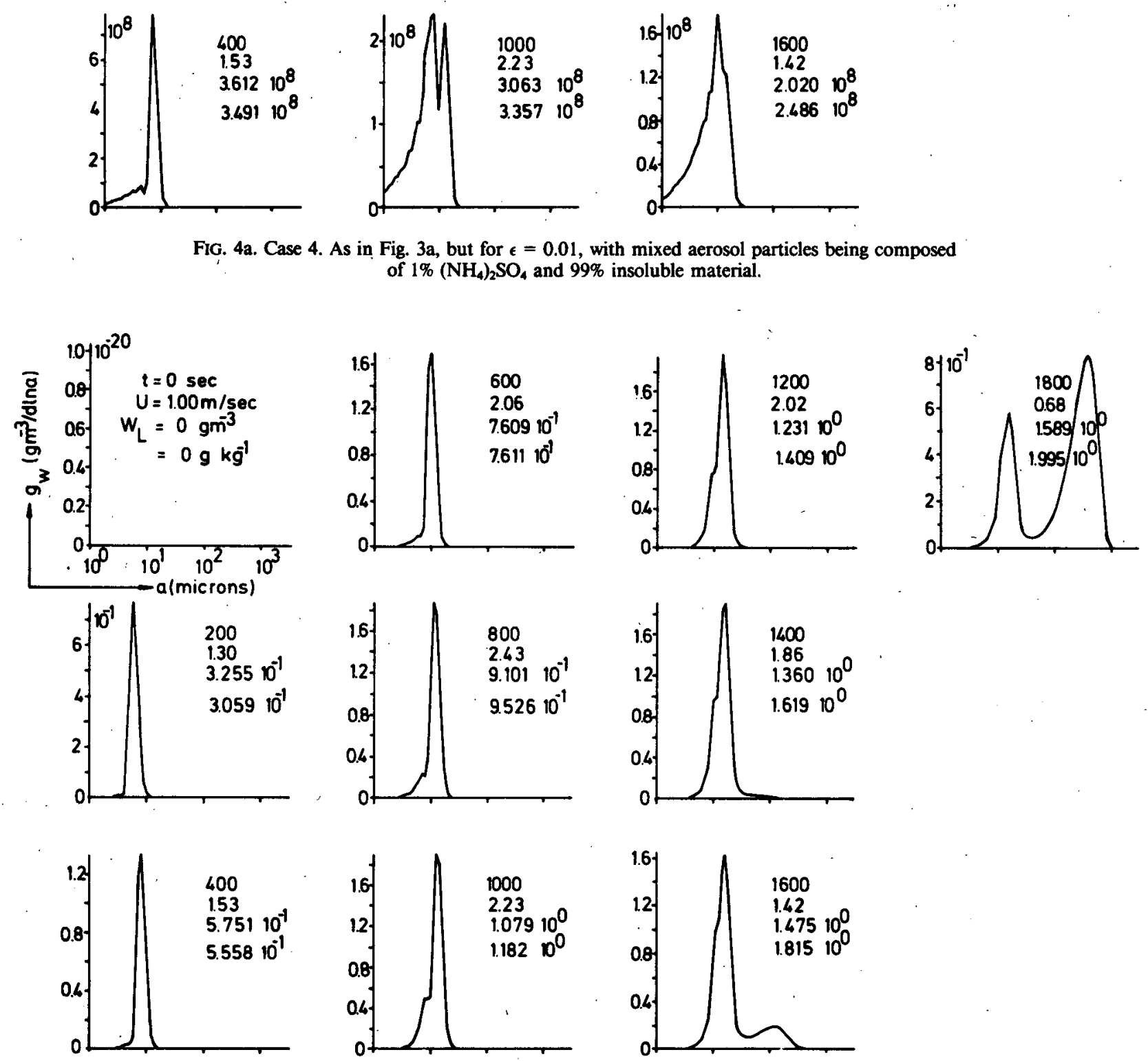

Fig. 4b. Case 4. As in Fig. 3b, but for conditions specified in Fig. 4a. 

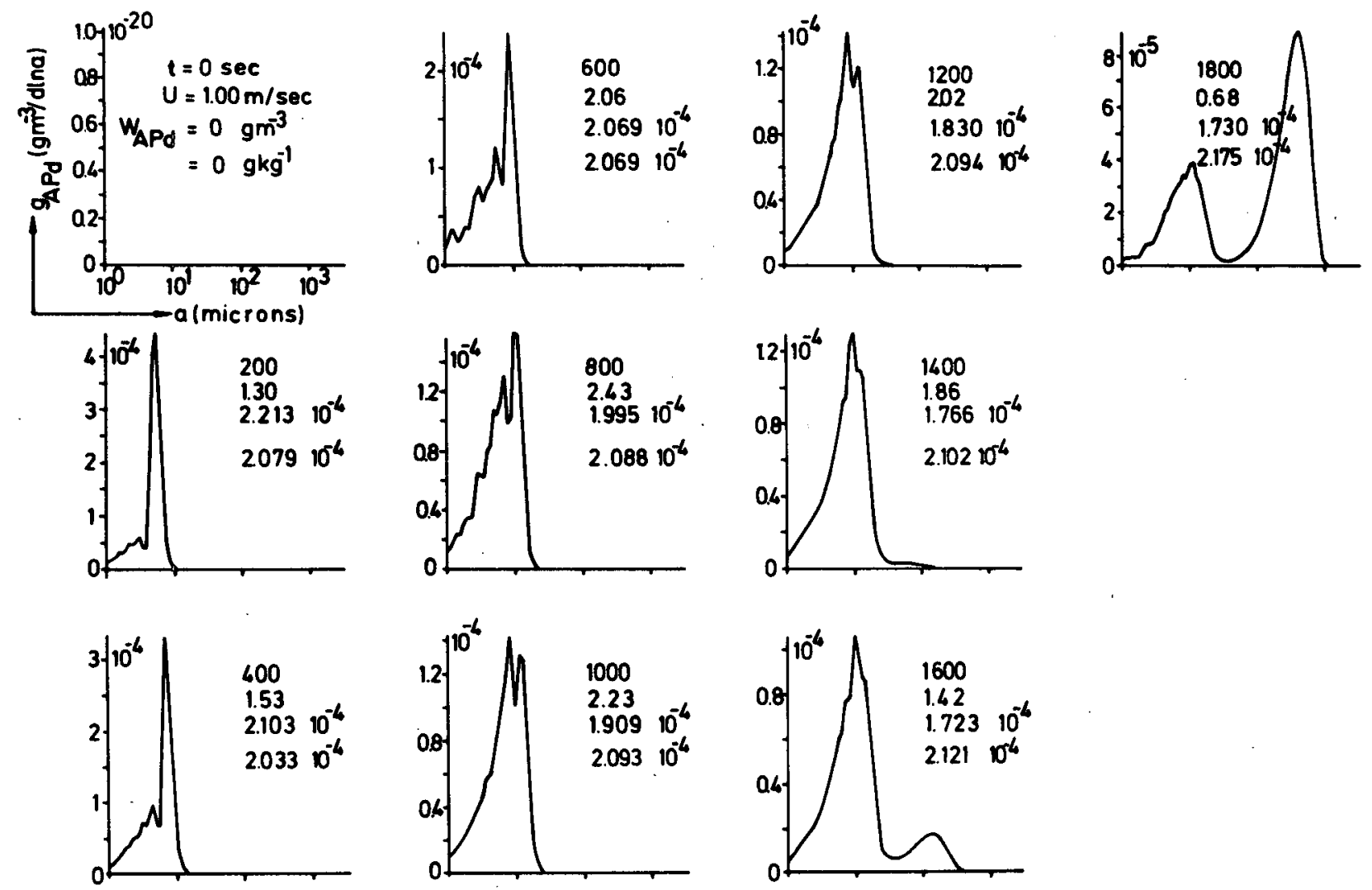

Fig. 4c. Case 4. As in Fig. 3c, but for drop size spectrum evolving in time as given in Figs. 4a, b.
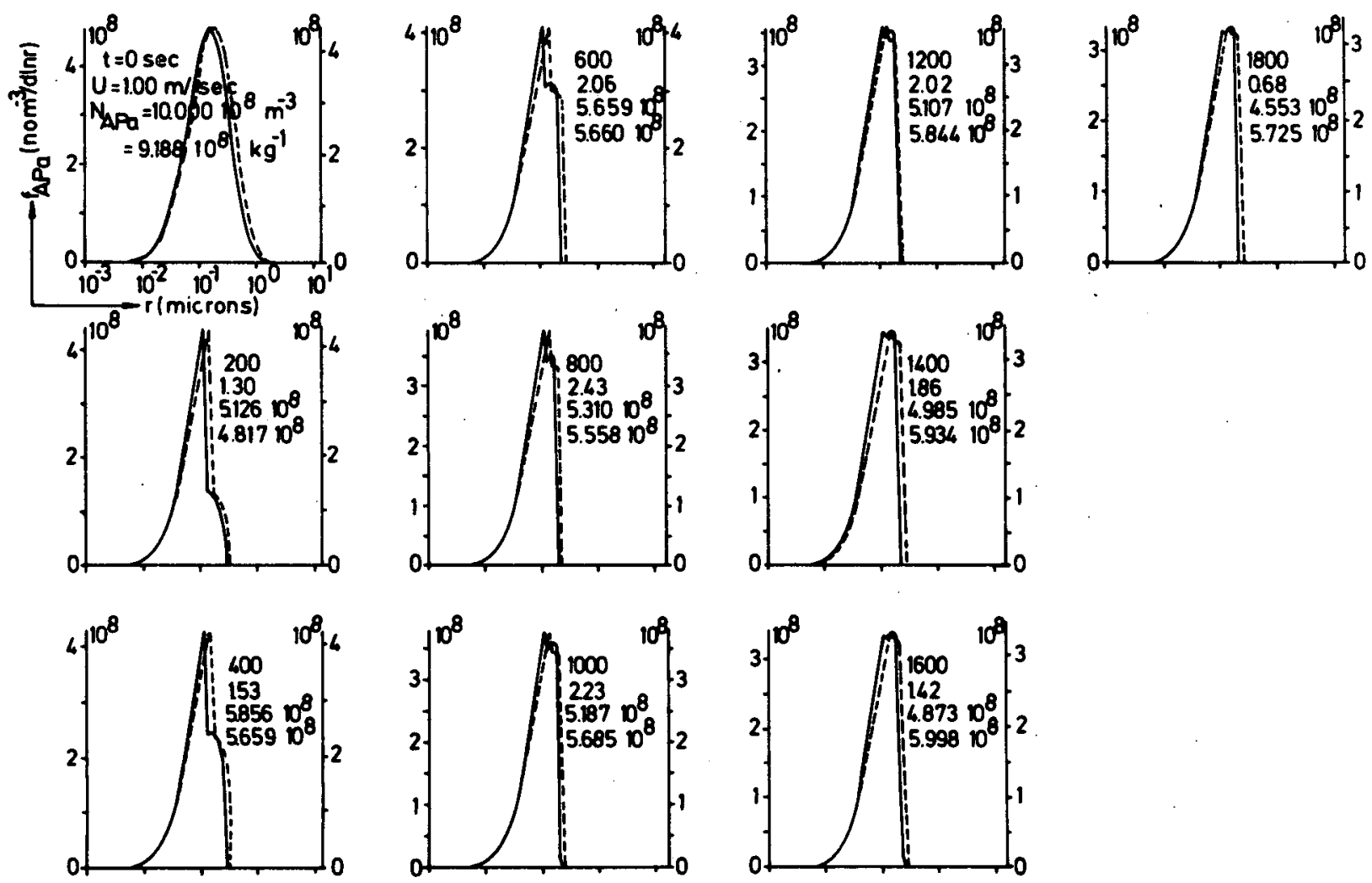

Fig. 4d. Case 4. As in Fig. 3d, but for conditions specified in Fig. 4a. 

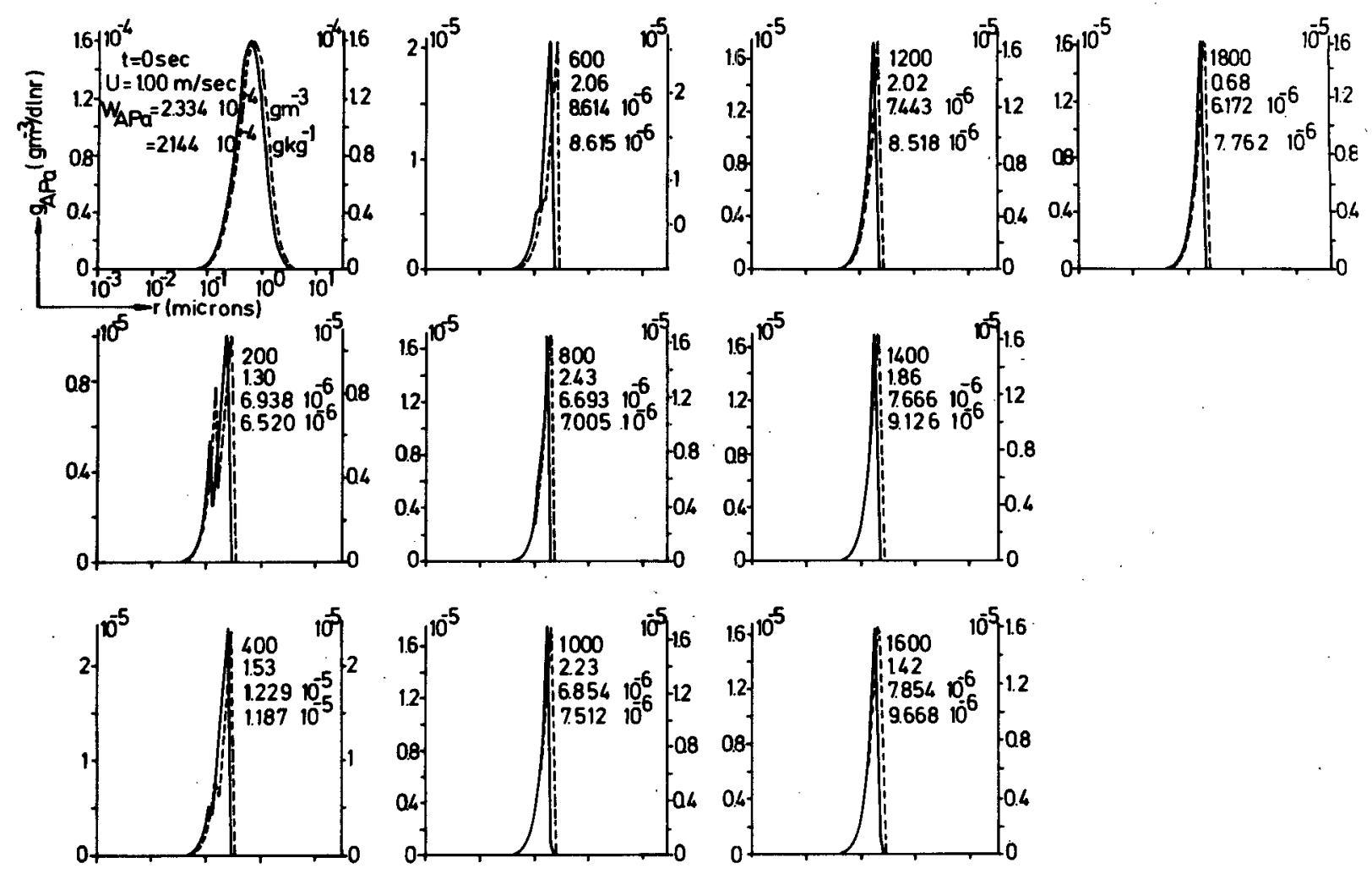

FIG. 4e. Case 4. As in Fig. 3e, but for conditions specified in Fig. 4a.

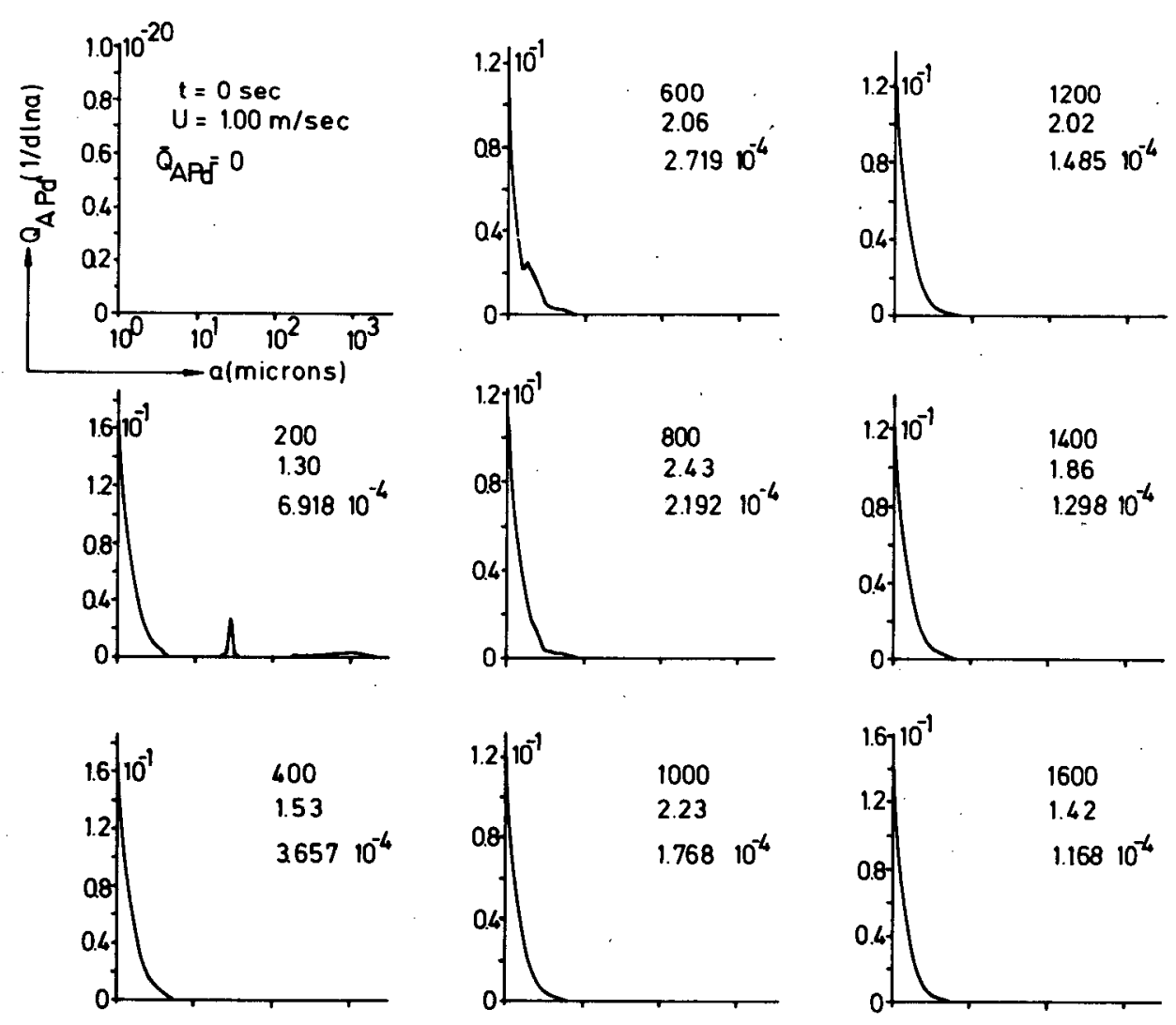

Fig. 4f. Case 4. As in Fig. 3f, but for conditions specified in Fig. 4a. 

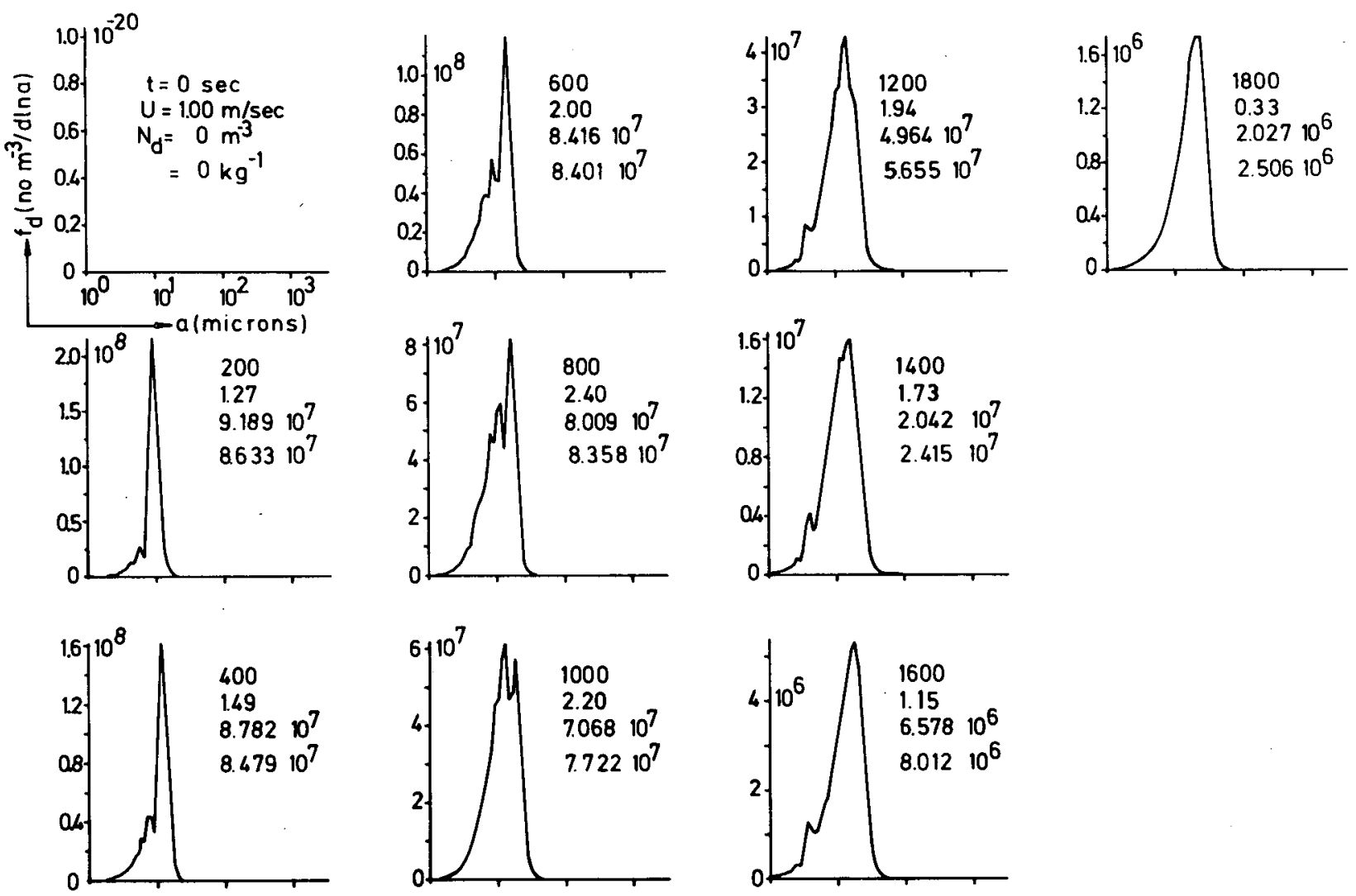

FIG. 5a. Case 5. As in Fig. 3a, but for an initial total particle concentration $N_{\mathrm{a}}=100 \mathrm{~cm}^{-3}$ and for $\epsilon=1.0,\left(\mathrm{NH}_{4}\right)_{2} \mathrm{SO}_{4}$.


Fig. 5b. Case 5. As in Fig. 3b, but for conditions specified in Fig. 5a. 

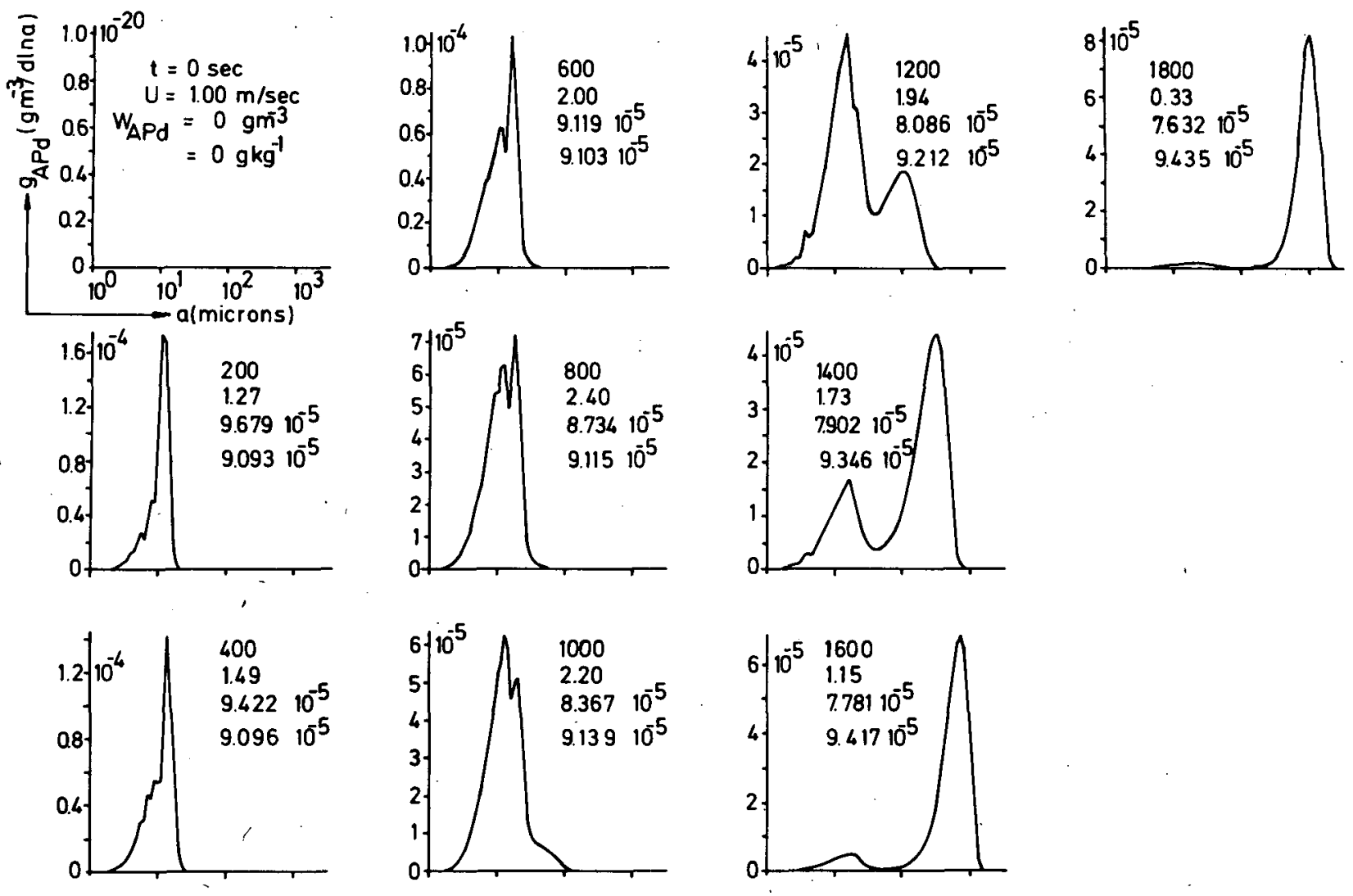

FIG. 5c. Case 5. As in Fig. 3c, but for drop size distribution evolving in time as given by Figs. 5a, b.
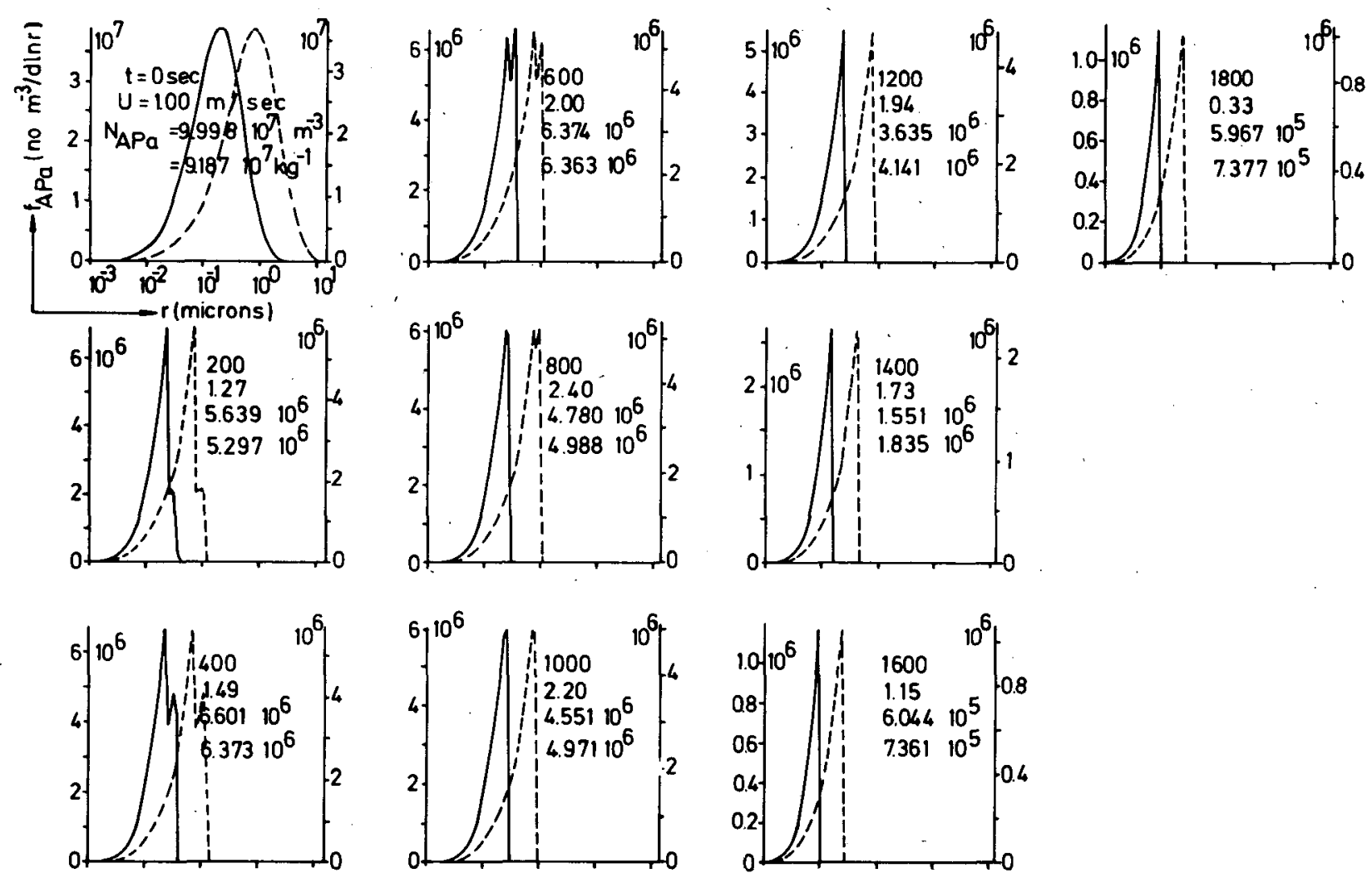

FIG. 5d. Case 5. As in Fig. 3d, but for conditions specified in Fig. 5a. 

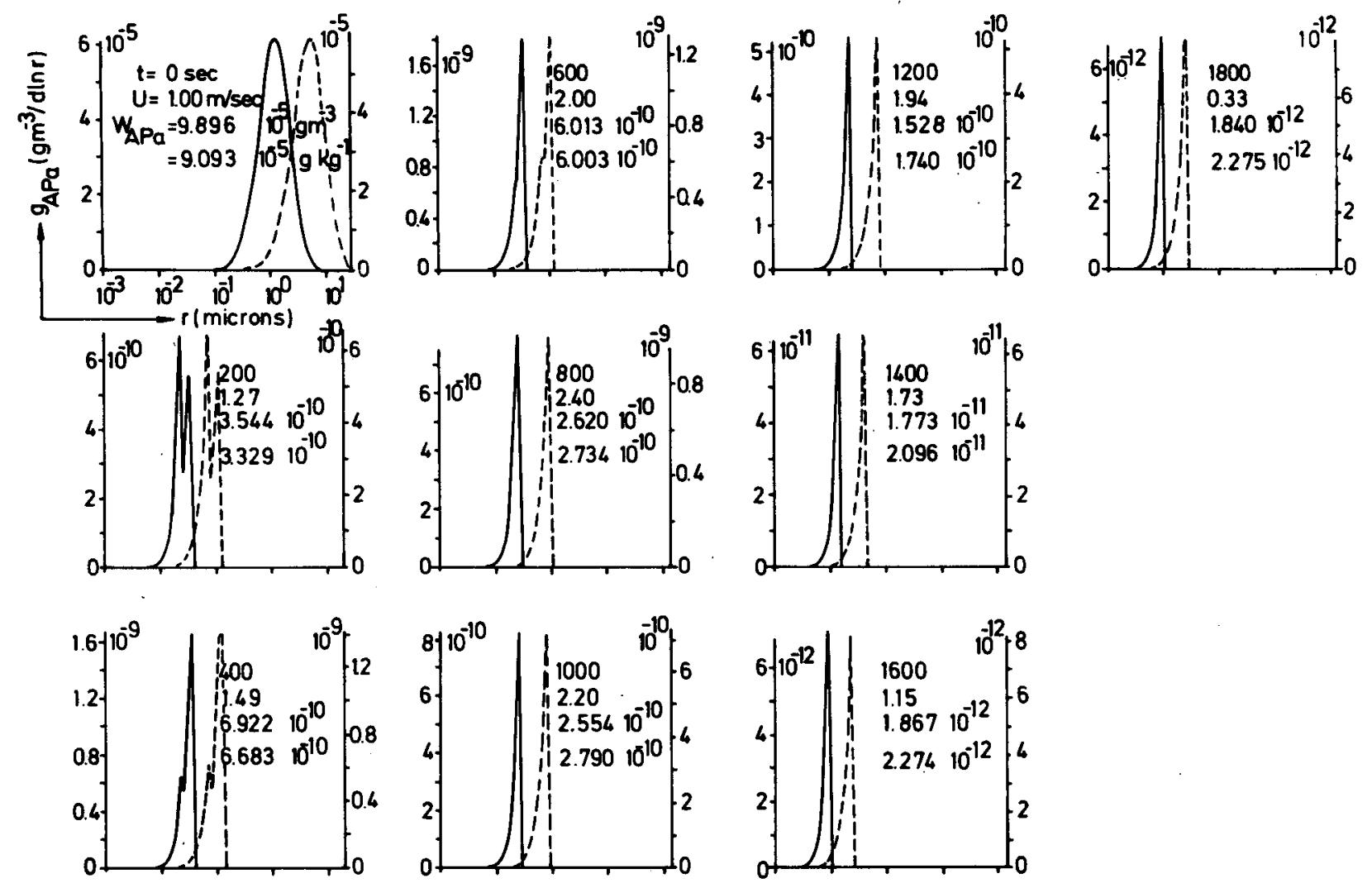

Fig. 5e. Case 5. As in Fig. 3e, but for conditions specified in Fig. 5a.
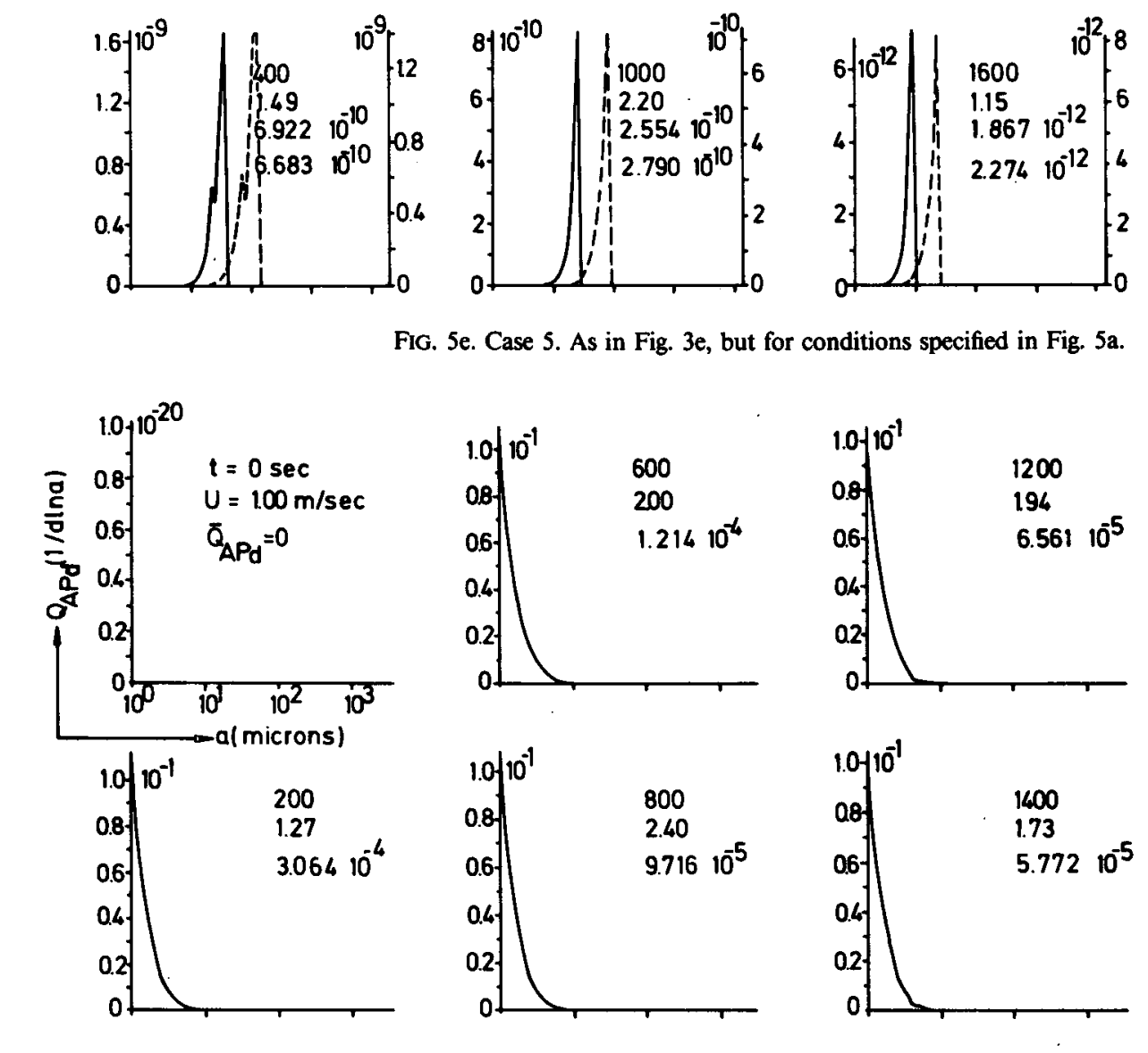

. Case S. As in Fig. 3e, but for conditions specifed in Fig. Sa.
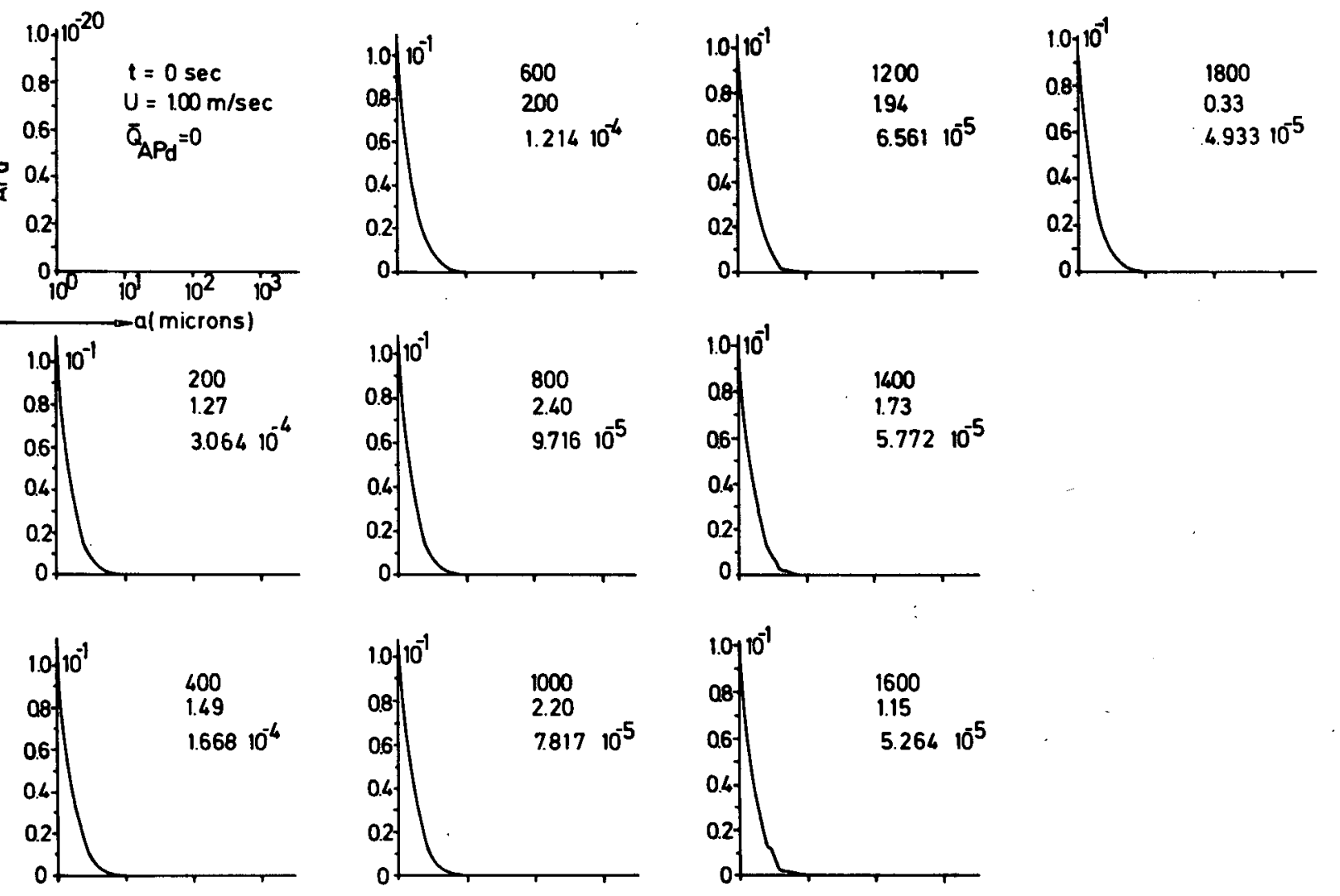

FiG. 5f. Case 5. As in Fig. 3f, but for conditions specified in Fig. 5a. 
During this "recovery" of the vapor field, the previously formed group of drops had time to grow by diffusion and thus to "detach" itself somewhat from the next following group of aerosol particles activated to drops. Evidence from field observations for such multiple peaks can, for example, be found in Fig. 7 of Ryan et al. (1972). We expect that the multiple peaks will disappear if the aerosol particles involved in the condensation mechanism have a chemical nature which varies from particle to particle and is not uniform (as assumed in the present and all previous condensation models) and if the turbulence in the cloud is allowed to mix the drops.

We also should emphasize that the disappearance of the multiple maxima and eventually the double maxima in the drop size distributions presented here are a result of the choice of increasingly broader drop size categories which "swallow up" the different peaks.

\section{Conclusions}

A theoretical model was formulated which involves a coupling of the condensation process and the collision-coalescence process for studying the fate of aerosol particles removed by cloud drops through nucleation scavenging and impaction scavenging. From this model a determination was made of the time evolution of aerosol particle mass scavenged by drops, and of the aerosol particle mass left unactivated in air as drop-interstitial aerosol. Our study suggests four phenomena. 1) The collision-coalescence process is responsible for a redistribution of the scavenged aerosol particle mass inside the cloud water in such a manner that the main aerosol particle mass is always associated with the main water mass, thus ensuring that if a cloud reaches the precipitation stage it also will return to the ground the main scavenged aerosol particle mass. This result has yet to be verified by field observations. 2) Although the main aerosol particle mass is contained in the large drops, the mass mixing ratio of the captured aerosol in the cloud water is larger inside small drops, implying that smaller drops are more contaminated than larger ones. This result is in good qualitative agreement with the field studies of Georgii and Wötzel (1970). 3) Inside a cloud a drop interstitial aerosol exists which consists of a particle population reduced in number concentration through nucleation scavenging by up to $94 \%$, and reduced in mass by several orders of magnitude, as based on the aerosol particle population outside the cloud. This result is in qualitative good agreement with the field studies of Radke (1983, his Fig. 2), if his approximate data for aerosol particles larger than $0.3 \mu \mathrm{m}$ are disregarded due to his admittedly still unresolved experimental difficulties, and if it is recalled that our computations were carried out for aerosol particles which all had the same composition; this is in contrast to the heterogeneous composition of natural aerosols. 4) Although the amount of aerosol mass scavenged by impaction cannot com- pletely be neglected in accounting for the total aerosol particle mass removed by clouds, our results show further that independent of composition the aerosol particle mass removed by nucleation scavenging is larger by several orders of magnitude than the aerosol particle mass removed by impaction scavenging inside clouds. This conclusion has been qualitatively verified by the field studies of Radke (1983) and Hegg and Hobbs (1983).

At this point it must be stressed that the authors are fully aware of the tentative nature of the values existing in literature for the efficiencies with which aerosol particles are scavenged by impaction with drops. In fact it has been suggested (Radke et al.; 1980; Barlow and Latham, 1983) that various factors existing in atmospheric clouds may cause the scavenging efficiency to be considerably larger than those found in the theoretical laboratory studies cited in Section 1. However, the present study shows quite convincingly that impaction scavenging contributes but little to the total amount of aerosol mass removed by nucleation scavenging. Thus, computations with an efficiency as large as near unity for all drops and aerosol sizes have yielded results which altered the present ones by less than $0.5 \%$. This finding is physically reasonable, as nucleation scavenging removes the main aerosol mass, leaving for impaction scavenging drop-interstitial-aerosol particles quite large in number but quite small in total mass. Even if this small mass would be removed by impaction scavenging with an efficiency of unity, the removed mass would still not contribute significantly to the total mass removed.

Also, at this point, it must be stressed that the present authors are fully aware of the many shortcomings of the "air-parcel-model" for studying the scavenging process as compared to using a two- or three-dimensional cloud dynamics model. However, it is argued here that the conclusions drawn from the present model are not specified to the dynamic model used and thus are expected to be verified by a twodimensional convective cloud model. On the other hand, there is no a priori difficulty in removing the air parcel dynamics from our presently used scavenging model and instead coupling our scavenging model with a more detailed cloud dynamics model. Such a coupling is planned for the near future.

Further, we must emphasize that the present study only applies to aerosol particles of uniform composition. Impaction scavenging may be considerably more prominent in removing aerosol particles if an external mixture exists in air of aerosol particles of very different chemical composition.

Also, we must stress again that the present model only applies to in-cloud scavenging and does not consider below-cloud scavenging. Again, in belowcloud scavenging, impaction scavenging may take a more prominent role than it does in in-cloud scavenging. 
Finally, it should be added that the present model can easily be applied to the scavenging of gases from the atmosphere which, once scavenged, will suffer the same redistribution among the various cloud drop size categories as the aerosol particles do. Such an application is presently also underway.

Acknowledgments. One of the authors (HRP) acknowledges the Atmospheric Sciences Section of the National Science Foundation which supported part of the present work under Grant ATM 81-15121.

$\begin{array}{ll}a, \bar{a} & \begin{array}{l}\text { drop radius, mean drop radius of } \\ \text { distribution }\end{array} \\ c_{p a} & \begin{array}{l}\text { specific heat of air } \\ \text { diffusivity of water vapor in air }\end{array}\end{array}$

$D_{v}^{*}$

$e, e_{\text {sat }, w} \quad$ water vapor pressure, saturation vapor

$E_{\mathrm{d}} \quad$ collection efficiency for drops colliding

$E_{\mathrm{AP}} \quad$ collection efficiency for drops colliding

$f_{\mathrm{APa}} \quad$ aerosol particle number distribution

$f_{\mathrm{d}}$

$F_{v}$

g

$g_{\text {APd }}$

$g_{w}(m)$

$g_{\mathrm{APa}}$

$K_{\mathrm{d}}$

$K_{\text {AP }}$

$K_{m}$

$k_{\mathrm{a}}$

$k_{\mathrm{a}}^{*} \quad=k_{\mathrm{a}}\left[\frac{a}{a+\Delta_{T}}+\frac{k_{\mathrm{a}}}{a \alpha_{T} \rho_{\mathrm{a}} c_{p \mathrm{a}}}\left(\frac{2 \pi M_{\mathrm{a}}}{\mathcal{R} T}\right)^{1 / 2}\right]^{-1}$

$L_{e} \quad$ latent heat of evaporation

\section{APPENDIX}

\section{Definition of Terms} $=D_{v}\left[\frac{a}{a+\Delta_{v}}+\frac{D_{v}}{a \alpha_{c}}\left(\frac{2 \pi M_{w}}{R T}\right)^{1 / 2}\right]^{-1}$

(Pruppacher and Klett, 1978, Eqs. 13-13) pressure over water with drops with aerosol particles function for aerosol particles in air

(Pruppacher and Klett, 1978, Eqs. 13-20)

$+0.308 X$, for $X>1.4$, with $X$

$=N_{\mathrm{Sc}}{ }^{1 / 3} N_{\mathrm{Re}}{ }^{1 / 2}$ (Pruppacher and

Klett, 1978 , p. 443)

acceleration of gravity

aerosol particle mass distribution

function for aerosol in cloud water

cloud drop mass distribution function

$=m\left[1-Q_{\mathrm{APd}}(m)\right] f_{\mathrm{d}}(m)$

aerosol particle mass distribution

function for aerosol in air

collection kernel for drops colliding

with drops

collection kernel for drops colliding

with aerosol particles

turbulent eddy diffusion coefficient

thermal conductivity of air $m, m_{\mathrm{AP}}$

$m_{N}, m_{s}$
$M_{w}, M_{\mathbf{a}}$ $M_{s}$

$N_{\mathrm{a}}, N_{\mathrm{d}}$

$N_{\text {Sc }}$

$Q_{\mathrm{APd}}(m)$

$\bar{Q}_{\text {APd }}$

$Q_{\mathrm{APa}}\left(m_{\mathrm{AP}}\right)$

$r, r_{N}$

$\mathscr{R}$

$R$

$T, T_{v}$

$U$

$V(m)$

V

$w_{\mathrm{APd}}, w_{\mathrm{APa}}$

$w_{L}, w_{\mathrm{LAP}}$

$z$

$\alpha_{T}, \alpha_{c}$

$\Gamma$

$\Delta_{v}, \Delta_{T}$

$\epsilon$

mass of drop, of growing aerosol particle, of dry aerosol particle, of water-soluble component in aerosol particle

molecular weight of water, salt, air

total number of aerosol particles per unit volume of air (per $\mathrm{kg}$ of air), total number of drops per unit volume of air (per $\mathrm{kg}$ of air)

Schmidt number $=\nu_{\mathrm{a}} / D_{v}$ aerosol mass mixing ratio distribution function $=g_{\mathrm{APd}}(m) / m f_{\mathrm{d}}(m)$

total mass mixing ratio of aerosol particles in cloud water

aerosol mass mixing ratio distribution function $=g_{\mathrm{APa}}\left(m_{\mathrm{AP}}\right) / m_{\mathrm{AP}} f_{\mathrm{APa}}\left(m_{\mathrm{AP}}\right)$ radius of growing aerosol particle, radius of dry aerosol particle universal gas constant radius of updraft

absolute temperature, virtual temperature

updraft velocity

terminal velocity of drops

velocity field of air

aerosol mass in drops, in air, per unit volume (per $\mathrm{kg}$ ) of air

liquid water content of drop cloud, of unactivated aerosol particles

vertical coordinate

thermal accommodation coefficient, condensation coefficient

gamma function

vapor jump distance, thermal jump distance

composition of aerosol particle $=m_{s} m_{N}^{-1}$

$\Phi_{s} \quad$ osmotic coefficient

$\mu \quad$ entrainment factor $=\left(1 / m_{\mathrm{a}}\right)\left(d m_{\mathrm{a}} / d z\right)$, with $m_{\mathrm{a}}=$ mass of air parcel

$\nu_{a} \quad$ kinematic viscosity of air

$\sigma_{i} \quad$ dispersion of drop size distribution

$\sigma_{w / a} \quad$ surface tension of water

$\rho_{w} \quad$ density of water

$\rho_{\mathrm{AP}}$

$\psi$ lact

$\left.\psi\right|_{\text {cond/eva }}$

$\left.\psi\right|_{\mathrm{AP}, \text { coll }}$

$\left.\psi\right|_{\text {d, coal }}$

$\left.\psi\right|_{\text {d, break up }}$

$\psi$ density of dry aerosol particle

change due to activation of aerosol particles to drops

change due to condensation and/or evaporation

change due to aerosol particle collection

change due to collision and coalescence of drops

change due to drop break-up

refers to the time rate of change of the functions $f_{\mathrm{d}}, g_{\mathrm{APd}}, f_{\mathrm{APa}}, g_{\mathrm{APa}}, Q_{\mathrm{APa}}$, $Q_{\mathrm{APd}}, m$, or $m_{\mathrm{AP}}$ 


\section{REFERENCES}

Barlow, A. K., and J. Latham; 1983: A laboratory study of the scavenging of submicron aerosol by charged raindrops. Quart. J. Roy. Meteor. Soc., 109, 763-770.

Berry, E. X., 1974a: An analysis of cloud drop growth by collection. Part Il: Single initial distributions. J. Atmos. Sci., 31, 18251831.

- 1974b: An analysis of cloud drop growth by collection. Part III: Accretion on self collection. J. Atmos. Sci., 31, 21182126.

$\longrightarrow$ 1974c: An analysis of cloud drop growth by collection. Part IV: A new parameterization. J. Atmos. Sci., 31, 2127-2135.

- - and R. L. Reinhardt, 1974: An analysis of cloud drop growth by collection. Part I: Double distribution. J. Atmos. Sci., 31, 1814-1824.

Carstens, J. C., and J. J. Martin, 1982: In-cloud scavenging by thermophoresis, diffusiophoresis and Brownian diffusion. $J$ Atmos. Sci., 39, 1124-1129.

Danielsen, E. F., R. Bleck and D. A. Morris, 1972: Hailgrowth by stochastic collection in a cumulus model. J. Atmos. Sci., 29, 135-155.

Davis, M. H., 1972: Collisions of small droplets: Gaskinetic effects. J. Atmos. Sci., 29, 911-915.

Deimendjian, D., 1969: Electromagnetic Scattering on Spherical Polydispersions. American Elsevier, 290 pp.

Flossmann, A., 1985: A theoretical investigation of the removal of atmospheric trace constituents by means of a dynamic model. Ph.D. thesis, Meteor. Institut, Joh. Gutenberg University, Mainz, FRG. [Available from University of Mainz.]

Georgii, H. W., and D. Wötzel, 1970: On the relations between drop size and concentration of trace gas elements in rain water. J. Geophys. Res., 75, 1727-1731.

Grover, S. M., H. R. Pruppacher and A. E. Hamielec, 1977: A numerical determination of the efficiency with which spherical aerosol particles collide with spherical water drops due to inertial impaction and phoretic and electric forces. J. Atmos. Sci., 34, 1655-1663.

Hall, W. D., 1980: A detailed microphysical model within a twodimensional dynamic framework: Model description and preliminary results. J. Atmos. Sci., 37, 2486-2507.

Hampl, V., M. Kerker, D. D. Cooke and E. Matijevic, 1971: Scavenging of aerosol particles by a falling water droplet. $J$. Atmos. Sci., 28, 1211-1221.

Hegg, D. A., and P. V. Hobbs, 1983: Preliminary measurements on the scavenging of sulfate and nitrate by clouds. Precipitation Scavenging, Dry Deposition, and Resuspension, Vol. I, Elsevier Science, 78-89.

Jonas, P. R., 1972: The collision efficiency of small drops. Quart. J. Roy. Meteor. Soc., 98, 681-683.

Kerker, M., and V. Hampl, 1974: Scavenging of aerosol particles by a falling water drop and calculation of washout coefficients. J. Atmos. Sci., 31, 1368-1376.

Klett, J. D., and M. H. Davis, 1973: Theoretical collision efficiencies of cloud droplets at small Reynolds numbers. J. Atmos. Sci., 30, 107-117.

Lai, K. U., N. Dayan and M. Kerker 1978: Scavenging of aerosol particles by a falling water drop. J. Atmos. Sci., 35, 674-682.

Lee, I. Y., and H. R. Pruppacher, 1977: A comparative study on the growth of cloud drops by condensation using an air parcel model with and without entrainment. Pure Appl. Geophys., 115, 523-545.

- - G. Hänel and H. R. Pruppacher, 1980: A numerical determination of the evolution of cloud drop spectra due to condensation on natural aerosol particles. J. Atmos. Sci., 37, 1839-1853.

Leong, K. H., K. V. Beard and H. T. Ochs, 1982: Laboratory measurements of particle capture by evaporating cloud drops. J. Atmos. Sci., 39, 1130-1140.

Lin, C. L., and S. C. Lee, 1975: Collision efficiencies of water drops in the atmosphere. J. Atmos. Sci., 32, 1412-1418.

Mason, B. J., and P. R. Jonas, 1974: The evolution of droplet spectra and large droplets by condensation in cumulus clouds. Quart. J. Roy. Meteor. Soc., 100, 23-38.

Pruppacher, H. R., and J. D. Klett, 1978: Microphysics of Clouds. D. Reidel, 714 pp.

Radke, L., 1983: Preliminary measurements of the size distribution of cloud interstitial aerosol. Precipitation Scavenging. Dry Deposition and Resuspension, Vol. I, Elsevier, 71-78.

$\longrightarrow$, P. V. Hobbs and M. W. Eltgrowth, 1980: Scavenging of aerosol particles by precipitation. J. Appl. Meteor., 19, 715722.

Ryan, R. T., H. H. Blau, P. C. v. Thüma and M. L. Cohen, 1972: Cloud microstructures as determined by an optical spectrometer. J. Appl. Meteor., 11, 149-156.

Schlamp, R. J., S. N. Grover, H. R. Pruppacher and A. E. Hamielec, 1976: A numerical investigation of the effect of electric charges and vertical electric fields on the collision efficiency of cloud drops. J. Atmos. Sci., 33, 1747-1755.

Shafrir, V., and T. Gal-Chen, 1971: A numerical study of collision efficiencies and coalescence parameters for droplet pairs and with radii up to 300 microns. J. Atmos. Sci., 28, 741-751:

Smolarkiewicz, P. K., 1983: A simple, positive definitive advection scheme with small implicit diffusion. Mon. Wea. Rev., 111, $479-486$.

Wang, P. K., and H. R. Pruppacher, 1977: An experimental determination of the efficiency with which aerosol particles are collected by water drops in subsaturated air. J. Atmos. Sci., 34, 1664-1669.

- S. N. Grover and H. R. Pruppacher, 1978: On the effect of electric charges on the scavenging of aerosol particles by cloud and small rain drops. J. Atmos. Sci., 35, 1735-1743.

Warner, J., 1969: The microstructure of cumulus clouds. Part II: The effect on drop size distribution of cloud nucleus spectrum and updraft velocity. J. Atmos. Sci., 26, 1272-1282.

, 1973: The microstructure of cumulus clouds. Part IV: The effect on the droplet spectrum. of mixing between cloud and environment. J. Atmos. Sci., 30, 256-261. 